\title{
Impact of Left-Turn Phasing on Older and Younger Drivers at High-Speed SignaLIZED INTERSECTIONS
}

\author{
Sponsored by \\ the lowa Department of Transportation
}

(CTRE Project 03-149)

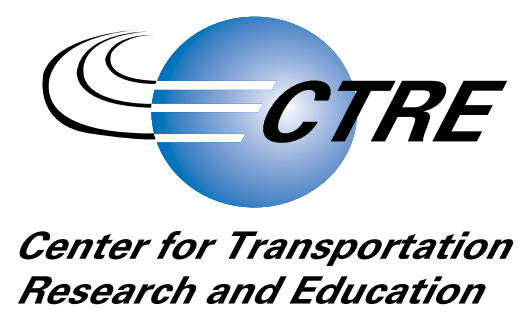

IOWA STATE UNIVERSITY

Final Report • A August 2004 


\section{Disclaimer Notice}

The opinions, findings, and conclusions expressed in this publication are those of the authors and not necessarily those of the Iowa Department of Transportation. The sponsor assumes no liability for the contents or use of the information contained in this document. This report does not constitute a standard, specification, or regulation. The sponsor does not endorse products or manufacturers.

\footnotetext{
About CTRE/ISU

The mission of the Center for Transportation Research and Education (CTRE) at Iowa State University is to develop and implement innovative methods, materials, and technologies for improving transportation efficiency, safety, and reliability while improving the learning environment of students, faculty, and staff in transportation-related fields.
} 
Technical Report Documentation Page

\begin{tabular}{|c|c|c|c|}
\hline 1. Report No. & 2. Government Accession No. & \multicolumn{2}{|c|}{ 3. Recipient's Catalog No. } \\
\hline \multirow{2}{*}{\multicolumn{2}{|c|}{$\begin{array}{l}\text { 4. Title and Subtitle } \\
\text { Impact of Left-Turn Phasing on Older and Younger Drivers at High-Speed } \\
\text { Signalized Intersections }\end{array}$}} & \multicolumn{2}{|l|}{$\begin{array}{l}\text { 5. Report Date } \\
\text { August } 2004\end{array}$} \\
\hline & & \multicolumn{2}{|c|}{ 6. Performing Organization Code } \\
\hline \multicolumn{2}{|l|}{$\begin{array}{l}\text { 7. Author(s) } \\
\text { Shauna L. Hallmark and Kim Mueller }\end{array}$} & \multicolumn{2}{|c|}{$\begin{array}{l}\text { 8. Performing Organization Report No. } \\
\text { CTRE Project 03-149 }\end{array}$} \\
\hline \multicolumn{2}{|l|}{$\begin{array}{l}\text { 9. Performing Organization Name a } \\
\text { Center for Transportation Research an } \\
\text { Iowa State University } \\
\text { 2901 South Loop Drive, Suite } 3100 \\
\text { Ames, IA 50010-8634 }\end{array}$} & \multicolumn{2}{|c|}{ 11. Contract or Grant No. } \\
\hline \multicolumn{2}{|c|}{$\begin{array}{l}\text { 12. Sponsoring Organization Name and Address } \\
\text { Iowa Department of Transportation } \\
800 \text { Lincoln Way } \\
\text { Ames, IA } 50010\end{array}$} & \multicolumn{2}{|c|}{$\begin{array}{l}\text { 13. Type of Report and Period Covered } \\
\text { Final Report }\end{array}$} \\
\hline \multicolumn{4}{|c|}{$\begin{array}{l}\text { 15. Supplementary Notes } \\
\text { Visit www.ctre.iastate.edu for color PDF files of this and other research reports. }\end{array}$} \\
\hline \multicolumn{4}{|c|}{$\begin{array}{l}\text { 16. Abstract } \\
\text { Several recent studies have demonstrated differences in safety between different types of left-turn phasing-protected, permitted, and } \\
\text { protected/permitted phasing. The issue in question is whether older and younger drivers are more affected by a particular type of left- } \\
\text { turn phasing at high-speed signalized intersections and whether they are more likely to contribute to a left-turn related crash under a } \\
\text { specific type of left-turn phasing. } \\
\text { This study evaluated the impact of different types of left-turn phasing on older and younger drivers at high-speed signalized } \\
\text { intersections in Iowa. High-speed signalized intersections were of interest since oncoming speeds and appropriate gaps may be more } \\
\text { difficult to judge for older drivers and those with less experience. A total of } 101 \text { intersections from various urban locations in Iowa with } \\
\text { at least one intersecting roadway with a posted speed limit of } 45 \text { mph or higher were evaluated. Left-turn related crashes from } 2001 \text { to } \\
2003 \text { were evaluated. Left-turn crash rate and severity for young drivers (14- to } 24 \text {-year-old), middle-age drivers (25- to } 64 \text {-year-old), } \\
\text { and older drivers (65 years and older) were calculated. } \\
\text { Poisson regression was used to analyze left-turn crash rates by age group and type of phasing. Overall, left-turn crash rates indicated that } \\
\text { protected phasing is much safer than protected/permitted and permitted phasing. Protected/permitted phasing had the highest left-turn } \\
\text { crash rates overall. }\end{array}$} \\
\hline $\begin{array}{l}\text { 17. Key Words } \\
\text { crash rate-high-speed signalized in } \\
\text { phasing_oncoming traffic-permit } \\
\text { protected/permitted phasing }\end{array}$ & $\begin{array}{l}\text { tion—left-turn crash-left-turn } \\
\text { asing—-protected phasing- }\end{array}$ & $\begin{array}{l}\text { 18. Distribution } \\
\text { No restrictions. }\end{array}$ & \\
\hline $\begin{array}{l}\text { 19. Security Classification (of this } \\
\text { report) }\end{array}$ & $\begin{array}{l}\text { 20. Security Classification (of this } \\
\text { page) }\end{array}$ & 21. No. of Pages & 22. Price \\
\hline Unclassified. & Unclassified. & 73 & NA \\
\hline
\end{tabular}




\title{
IMPACT OF LEFT-TURN PHASING ON OLDER AND YOUNGER DRIVERS AT HIGH-SPEED SIGNALIZED INTERSECTIONS
}

\author{
CTRE Project 03-149 \\ Principal Investigator \\ Shauna L. Hallmark \\ Assistant Professor, Department of Civil, Construction and Environmental Engineering \\ Iowa State University \\ Research Assistant \\ Kim Mueller

\begin{abstract}
Preparation of this report was financed in part through funds provided by the Iowa Department of Transportation through its research management agreement with the Center for Transportation Research and Education.
\end{abstract} \\ Center for Transportation Research and Education \\ Iowa State University \\ 2901 South Loop Drive, Suite 3100 \\ Ames, IA 50010-8634 \\ Phone: 515-294-8103 \\ Fax: 515-294-0467 \\ www.ctre.iastate.edu
}

Final Report - August 2004 


\section{TABLE OF CONTENTS}

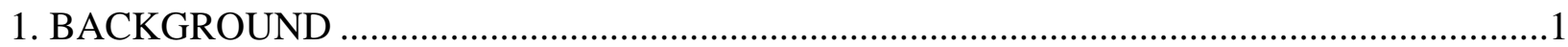

1.1 Crash Experience for Older Drivers ...................................................................1

1.2 Crash Experience for Younger Drivers...............................................................4

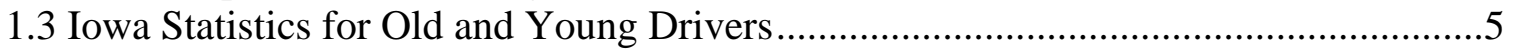

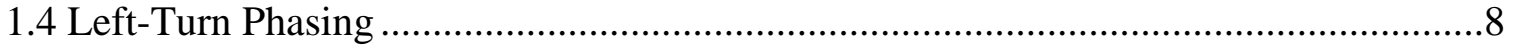

1.4.1 Safety Performance of Left-Turn Phasing ..............................................8

1.4.2 Left-Turn Phasing Guidelines..................................................................9

1.4.3 Driver Understanding of Left-Turn Control Displays ...............................12

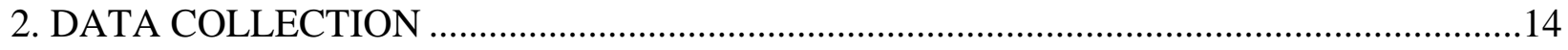

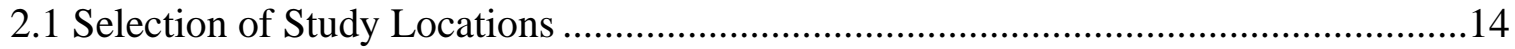

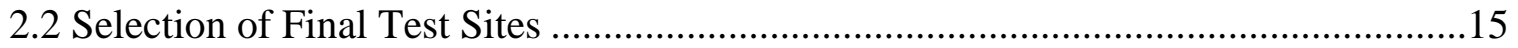

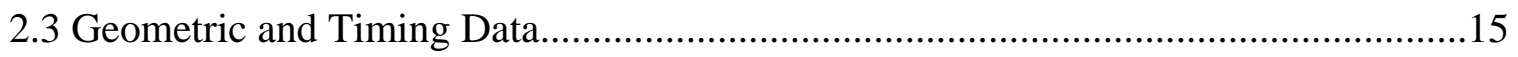

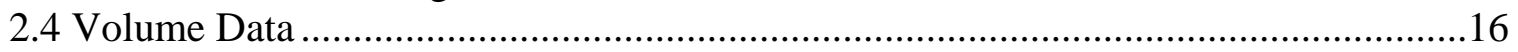

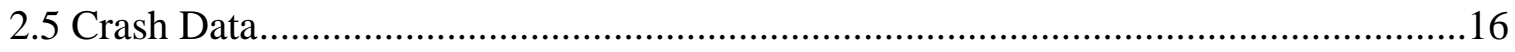

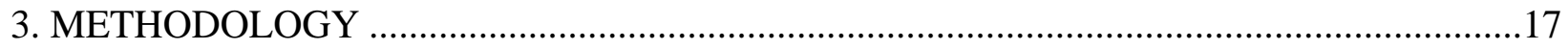

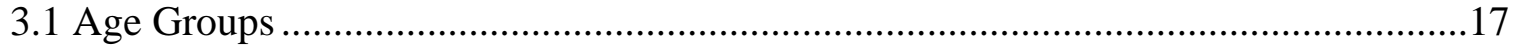

3.2 Left-turn Crashes ..............................................................................................17

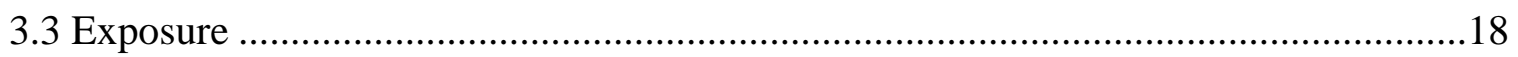

3.4 Calculation of Exposure by Age Group...........................................................19

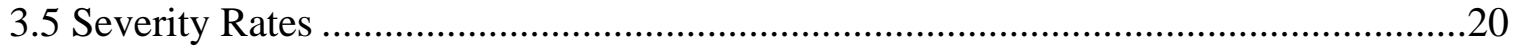

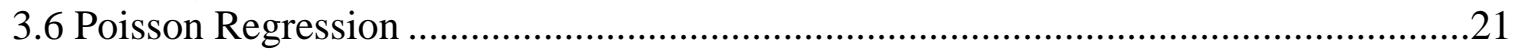

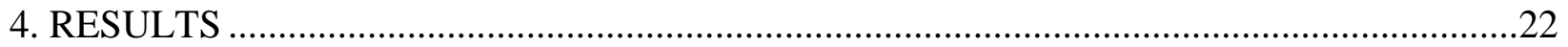

4.1 Left-turn Crash Rates by Type of Phase ..............................................................22

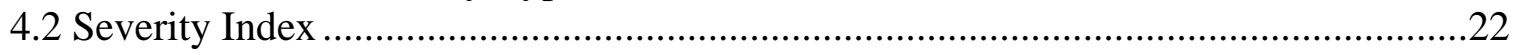

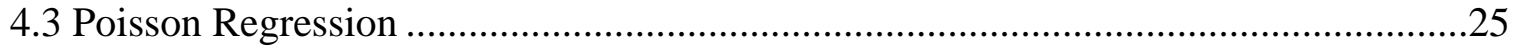

5. CONSIDERATION OF REAR-END CRASHES UNDER DIFFERENT TYPES OF LEFT-

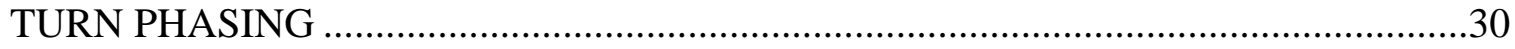

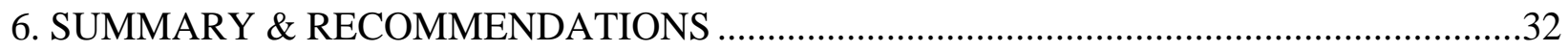

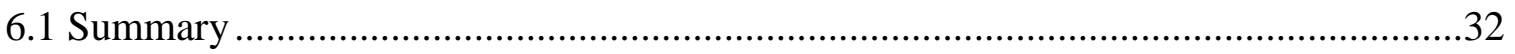

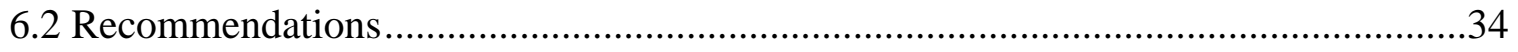


REFERENCES

APPENDIX A: LIST OF INTERSECTION LOCATIONS

APPENDIX B: LOCATION OF HIGH-SPEED INTERSECTIONS .42

APPENDIX C: IN-DEPTH DESCRIPTION OF METHODOLOGY .51

APPENDIX D: CODE ASSIGNING CONTRIBUTING CIRCUMSTANCE IN CRASH DATABASE FROM METADATA FOR 2001 CRASHES. 


\section{LIST OF FIGURES}

Figure 1.1. Forecasted trend of percentage of persons aged 65 and older in Iowa........................1

Figure 1.2. Percentage of drivers age 65 \& older by county in Iowa (Falb 2004) ........................2

Figure 1.3. Crashes by age group with failure to yield ROW while making left turn (Falb 2004).7

Figure 1.4. Number of passengers in vehicle at time of crash by age group (Naraghi and

Souleyrette 2004) .7

Figure 1.5. Left-turn phase flow chart (Upchurch 1986) ......................................................11

\section{LIST OF TABLES}

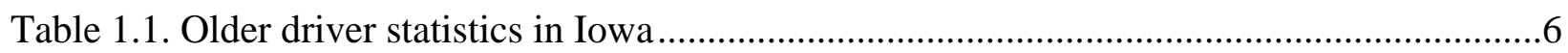

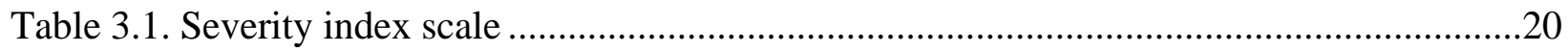

Table 4.1. Left-turn crash rates by type of phasing and by age group......................................22

Table 4.2. Average number and type of injuries per left-turn crash by type of phasing ..............23

Table 4.3. Average number and type of injuries per left-turn crash by age group .......................23

Table 4.4. Average severity for left-turn crashes by type of phasing ........................................24

Table 4.5. Average severity by age group .....................................................................24

Table 4.6. Average severity by type of phasing and by age group ..........................................24

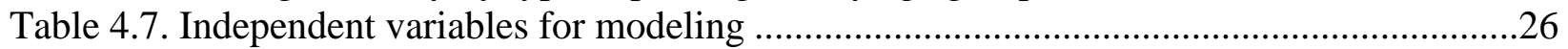

Table 4.8. Best fit model...........................................................................................27

Table 4.9. Expected left-turn crash rates and confidence intervals when the opposing AADT is

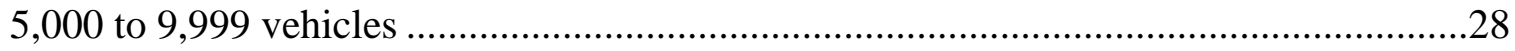

Table 5.1. Rear-end crash rate by type of left-turn phasing.....................................................31

Table C.1. Model variables used to asses goodness of fit ......................................................58

Table C.2. Best fit model ................................................................................................59

Table C.3. Contrast results using the likelihood ratio test .....................................................59

Table C.4. Expected crash rates and confidence intervals..................................................60 


\section{ACKNOWLEDGEMENTS}

The research team wishes to thank the Iowa DOT for support of this project. Special thanks to Mr. Tom Welch, Dr. Michael Pawlovich, and Mr. Tim Simodynes for their assistance in completing the project. We would also like to thank all the engineers and technicians that supplied data for this research project. We especially would like to thank those who work for the city of Waterloo, who provided a significant number of the intersections included in this study. 


\section{EXECUTIVE SUMMARY}

Implementation of different types of left-turn phasing is often based on operational considerations. Several studies, however, have demonstrated differences in safety between different types of left-turn phasing. These studies have shown that protected phasing results in the lowest crash rate followed by protected/permitted and then permitted phasing results (Maze et al. 1994; Upchurch 1986; and Matthias et al. 1996).

Older drivers are more likely to have problems with left turns than younger drivers. Studies have shown that they are more likely to be involved in angle crashes and in crashes at intersections. Older drivers are also cited more often than other age groups for failure to yield right-of-way and for illegal or improper turns. Additionally, they have slower perception-reaction times and exhibit more difficulty selecting safe gaps and judging speeds of oncoming vehicles than younger drivers. Existing evidence indicates that older drivers are less likely to understand the meaning of different types of left-turn displays.

Younger drivers may also have problems with left turns. Lack of experience or risky driving behavior are often cited as reason for crash involvement among young drivers. When younger drivers are involved in a crash, they are more likely to be cited for exceeding the speed limit, following too closely, and being inattentive. Young drivers are much more likely to be cited for failing to yield the right-of-way, disregarding the traffic signal, and disregarding the stop or yield sign than other age groups.

This study evaluated the impact of different types of left-turn phasing on older and younger drivers at high-speed signalized intersections in Iowa. High-speed signalized intersections were of interest since oncoming speeds and appropriate gaps may be more difficult to judge for older drivers and those with less experience. A total of 101 intersections from various urban locations in Iowa with at least one intersecting roadway with a posted speed limit of $45 \mathrm{mph}$ or higher were evaluated. Left-turn related crashes from 2001 to 2003 were evaluated. Left-turn crash rate and severity for young drivers (14- to 24-year-old), middle-age drivers (25- to 64-year-old), and older drivers (65 years and older) were calculated.

The induced exposure method was used to estimate exposure. This method, as discussed in the report, uses two-vehicle crashes and assigns fault to one driver, based on whoever was determined to have caused the accident. The other driver is assigned the designation of "not-atfault.” Drivers who are "not-at-fault” are assumed to approximate the general population. Consequently, the percentage of drivers in a particular age category can be used to estimate exposure by age group.

Poisson regression was used to analyze left-turn crash rates by age group and type of phasing. Three age groups were evaluated: 15 to 24, 25 to 64, and 65+. Overall, left-turn crash rates indicated that protected phasing is much safer than protected/permitted and permitted phasing. Protected/permitted phasing had the highest left-turn crash rates overall. However, it should be noted that left-turn crash rates were calculated as crashes per million entering vehicles (MEV) of the approach in question and not left-turn volume, which was not available and could not be collected with project resources. Older drivers had the highest left-turn crash rates of all age groups for all types of phasing. For older drivers, crash rates were the highest at 
protected/permitted phasing, followed by permitted phasing. Of the three types of phasing, crash rates were the lowest at protected phasing for older drivers. Middle-aged drivers had the lowest crash rates under all types of phasing among the three age groups. Under the three different types of phasing, young drivers had the highest crash rate at protected/permitted phasing, followed by permitted phasing.

A severity index was also calculated for each crash by assigning points to each of five types of injuries. Protected/permitted phasing had the highest average severity index. The severity index was the lowest for permitted. Younger drivers had the highest severity per crash under all types of phasing. However, the number of occupants per vehicle is not included in the crash records and was not considered.

Rear-end crashes by type of phasing was also evaluated. The total number of rear-end crashes for each high-speed approach was used to calculate a rear-end crash rate by type of left-turn phasing. The rear-end crash rate was the highest for approaches with protected phasing. However, it should be noted that all rear-end crashes were used in the analysis since the crash data could not specifically relate rear-end crashes to left-turning vehicles. 


\section{BACKGROUND}

This study evaluated whether older and younger drivers are more affected by a particular type of left-turn phasing at high-speed signalized intersections and whether they are more likely to contribute to a left-turn related crash under a specific type of left-turn phasing. Background information on the crash experience of older and younger drivers is provided in the following sections.

\subsection{Crash Experience for Older Drivers}

According to National Highway Traffic Safety Administration (NHTSA 2002a), from 1992 to 2002, the number of people over 70 increased at a rate that was $27 \%$ higher than that for the total population. The number of licensed drivers 70 years and older increased by 32\% from 1991 to 2001, while the total number of licensed drivers increased only by $13 \%$. In Iowa, according to the United States Census Bureau (Long 1996), the percentage of the population who are 65-yearold and older is expected to increase from $15.2 \%$ in 1995 to $22.6 \%$ in 2025. Figure 1.1 shows the population trend of Iowa citizens who are 65 and older as a percentage of the state's population until the year 2025. Iowa ranks among the top five states in the percentage of persons who are 65-year-old and older (1998) (NHTSA 2000). Figure 1.2 shows percentage of older drivers by county in Iowa.

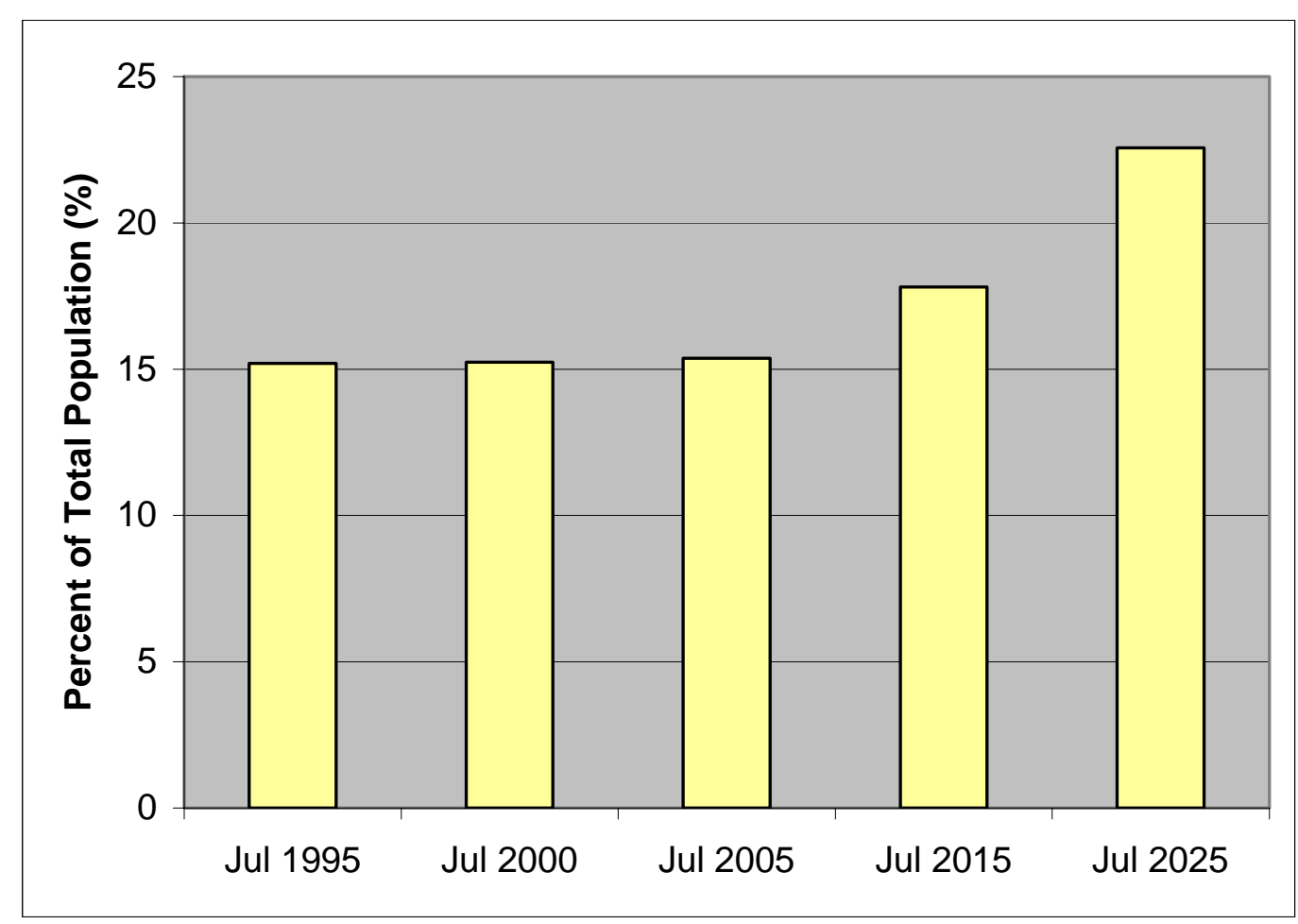

Figure 1.1. Forecasted trend of percentage of persons aged 65 and older in Iowa. 


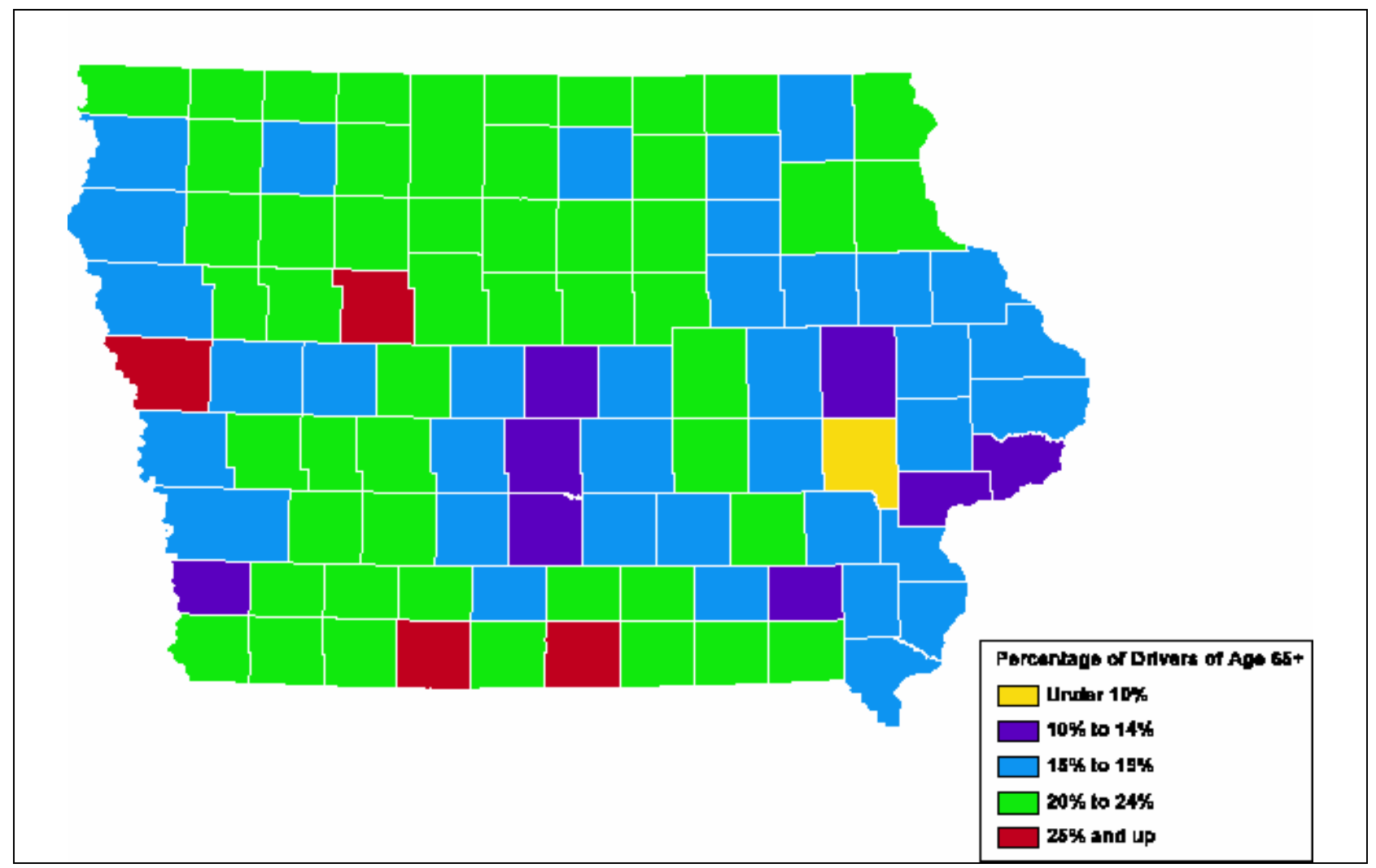

Figure 1.2. Percentage of drivers age 65 \& older by county in Iowa (Falb 2004)

The increase in the number of older drivers presents a traffic safety concern. According to a NHTSA report (2002a) in 2002, persons who are 70 and older accounted for only $9.0 \%$ of the total population; however, they represented $12.3 \%$ of total traffic fatalities and had the third highest fatality rate per 100,000 persons. The 16- to 20-year-old age group had the highest fatality rate per 100,000 persons, followed by the 21- to 34-year-old age group. Higher fatality rates may be attributed in part to deteriorating physical health as people age, leaving older persons more vulnerable to being seriously or fatally injured when involved in a crash. Mercier et al. (1999) looked at accident injury severity and found that, once older persons were involved in an accident, they were more at risk of injury than younger drivers. Li et al. (2003) found that fragility (injury propensity), measured by driver death per driver involved in a crash, begins to rise steadily around age 60 and then sharply increases for drivers 80 and older. The fatality rate for older drivers is particularly of concern since they typically drive less than drivers in other age groups, as reported in the 2001 National Household Trip Survey (NHTS). Li et al. (2003) also found that driver death rates per 100 million vehicle miles traveled (VMT) began to increase at age 65, with a dramatic increase after age 74 for both male and female drivers. Furthermore, the 80-year-old and older age group had the highest fatality rate per 100 million VMT, followed by the 75- to 79-year-old age group and the 16- to 19-year-old age group. In a study by McKelvey and Stamatiadis (1989), the fatality rate for older drivers who are 60 and older was found to be $33.7 \%$ higher than the average rate for all drivers based on thousands of licensed drivers and 81.3\% higher than the average rate for all drivers based on 100 million VMT. 
The characteristics of crashes involving older drivers have been found to be different than the characteristics of crashes involving middle age and young drivers. For example, older drivers are more likely to be involved in angle crashes according to several studies (FHWA 1995; Garber and Srinivason 1991a; McKelvey and Stamatiadis 1989; Abdel-Aty et al.1999) and less likely to be involved in rear-end crashes (FHWA 1995; Garber and Srinivason 1991a). Older drivers are also more likely to be involved in a multi-vehicle crash (McKelvey and Stamatiadis 1989; Preusser et al. 1998; Stamadiatis and Deacon 1997). An increase in involvement ratio for angle, sideswipe, and head-on crashes with age was reported by Garber and Srinivason (1991a).

Crash evidence indicates that older drivers experience difficulties at intersections. Several studies report that the percentage of crashes at intersections increases with age (Garber and Srinivason 1991a; Preusser et al. 1998; Abdel-Aty et al. 1999; Stamatiadis and Deacon 1995). Signalized intersections particularly appear to be problematic for the elderly when performing turning maneuvers, according to FHWA (1995) and Matthias et al. (1996). Stop-controlled intersections are problematic for older drivers as well. Garber and Srinivason (1991a) found that the percent of involvement in stop-controlled intersection crashes increases as age increases as well. In addition, Garber and Srinivason found that older drivers have higher involvement ratios at intersections located in rural areas than at intersections located in urban areas.

In addition to being involved in different types of accidents than younger drivers, when involved in a crash, an older driver is more likely to have committed a violation or be responsible (Garber and Srinivason 1991a; Preusser et al. 1998; Stamatiadis et al. 1991; McKelvey and Stamatiadis 1989). They are more likely to be cited for failure to yield right-of-way (FHWA 1995; FHWA 1993; Garber and Srinivason 1991a; McKelvey and Stamatiadis 1989; Stamatiadis et al. 1991; Abdel-Aty et al. 1999) and less likely to be cited for following too closely (FHWA 1993; Stamatiadis et al. 1991). In a study by McKelvey and Stamatiadis (1989), a significant number of accidents involving older drivers were attributed to the contributing factor categories of illness, fatigue, or inattention and obscured vision. At signalized intersections, older drivers were more likely to be cited for failure to yield, disregarding traffic signal, and making improper turns. At stop-controlled intersections, they were more likely to be cited for inattention, failure to yield, or disregarding stop sign (FHWA 1995). They were cited more often than other drivers for failure to yield right-of-way, illegal turns, and improper lane usage in head-on accidents (McKelvey and Stamatiadis 1989). Matthias et al. (1996) evaluated left-turn accidents by age group and found that $63 \%$ of drivers older than 70 were cited by an officer at the scene and received citations for improper turning twice as often as all other drivers combined. Additionally, Garber and Srinivason (1991a) found that the elderly are more likely to commit a traffic violation when they are required to yield to opposing traffic at intersections than other age groups. Stamatiadis et al. (1991) found that failure to yield for elderly drivers accounted for $40 \%$ or more of their accidents.

Left turns appear to be particularly problematic for older drivers. Research has shown that the potential of being involved in left-turn crashes increases with age (Garber and Srinivason 1991a; Matthias et al. 1996). In a study by Preusser et al. (1998), left-turn crashes accounted for about $7 \%$ of all fatal intersection crashes for the 40 to 49 age group, while left-turn crashes accounted for about $40 \%$ of all fatal intersection crashes for drivers who are 75 -year-old and older. In another study, Chandraratna et al. (2002) used logistic regression with fault status of the driver as 
an dependent variable and found that the odds of being responsible in left-turn crash against oncoming traffic was 3.2 times higher for drivers who are 65-year -old and older than for drivers younger than 65 . Drivers who are 85-year-old and older were 4 times more likely to be responsible than drivers in the 65-69 age group. The study also reported that for each one-year increase in age, beginning at 65, the risk of being involved in a left-turn crash increases by $8 \%$. In another study, FHWA (1995) evaluated Minnesota accident files to evaluate characteristics of older driver crashes at intersections and found that drivers who are 65-year-old and older were more likely to be involved in left-turn and angle collisions at both urban and rural locations than drivers in the 30-50 age group. Finally, Matthias et al. (1996), using crash data from the Arizona Department of Transportation (DOT), report that drivers over 70 years of age are involved in more left-turn crashes per mile than 20- to 69-year-old drivers, and left-turn crashes account for a much larger percentage of total accidents for drivers over the age of 65 than for any other age group.

Left-turn maneuvers may be problematic since older drivers have difficulty judging time to collision and acceptable gaps and, additionally, have slower response times (FHWA 1993). Cox and Cox (1998) found that it took longer for older drivers to execute a left turn. Other studies have indicated that difficulty in completing left-turn maneuvers by older drivers may be due to increased difficulty in judging gaps in the traffic stream (Staplin 1995; FHWA 1993; Scialfa et al. 1991). Oxley, Corben, and Fildes (2001) studied locations with a high number of crashes involving drivers who are 65 and older and found that selecting safe gaps in conflicting traffic at intersections is the most problematic maneuver for older drivers. Contributing factors found in crashes involving older drivers at intersections, other than gap selection, include lack of sight distance, high task complexity associated with other road users, high traffic volumes, high approach speeds of conflicting traffic, and wide roadways.

In a test study, Staplin (1995) asked test drivers to determine when they had a safe gap to make a left turn using oncoming test vehicles traveling at $30 \mathrm{mph}$ and then at $60 \mathrm{mph}$. As the speed of the oncoming vehicle increased, the younger drivers increased the minimum safe gap needed to turn left; however, the difference for older drivers did not increase significantly. FHWA (1993) found this pattern to be true for both left and right turn maneuvers, which shows that older drivers may rely primarily on vehicle separation distance to make a decision rather than on the speed of an oncoming vehicle. A study by Scialfa et al. (1991) asked observers to estimate the velocity of an isolated automobile traveling from 15 to $50 \mathrm{mph}$. Scialfa et al. determined that older drivers overestimated velocity at lower speeds and underestimated velocity at higher speeds and indicated that older drivers may be less able to judge oncoming vehicle speed. However, the differences between the older participants' speed estimations and the younger participants' speed estimations were small over the tested speed range.

\subsection{Crash Experience for Younger Drivers}

Research has found that young drivers are also over-involved in crashes. According to NHTSA (2002b), drivers who are 15- to 20-year-old accounted for 6.6\% of all drivers in 2001. In 2002, however, young drivers accounted for $14 \%$ of all drivers involved in fatal crashes and $16 \%$ of all drivers involved in police-reported crashes. Motor vehicle crashes are a concern for younger

drivers since crashes are the leading cause of death for young drivers. From 1992 to 2002, the 
age group consisting of 16- to 20-year-olds had the highest fatality rate per 100,000 population (NHTSA 2002a).

However, lack of experience or risky driving behavior is often cited as reasons for overinvolvement in crashes among young drivers, whereas for older drivers, over-involvement usually stems from decrease in physical, and sometimes mental, abilities. This contrast is noted in a study by Dissanayake et al. (1999), which listed speeding, reckless/aggressive driving, impaired driving, and lack of driving experience as the top four concerns for younger drivers.

Due to the concerns regarding lack of experience and risky driving behavior among young drivers, much of the current research addresses these concerns by analyzing graduated licensing program, which typically places restrictions on nighttime driving and/or the number of passengers in a vehicle during the intermediate stage. When specific types of crashes are studied, crashes such as run-off-the-road, head-on, and nighttime crashes are the focus of these studies since these types of crashes reflect the inexperience and risk-taking behavior of young drivers. For example, Abdel-Aty et al. (1999) found that young drivers are more likely to be involved in run-off-the-road crashes, overturn, and head-on crashes than their counterparts. In addition, Abdel-Aty et al. found that young drivers have a higher than average crash rate on weekends, which indicates the possible presence of alcohol among young drivers. Furthermore, since young drivers have a significantly higher percentage of crashes occurring at a speed that is greater than $10 \%$ higher than the posted speed limit, the increased probability of being involved in run-offthe-road and overturn crashes may be a result of the tendency of young drivers to speed. Risky behaviors may also explain why young drivers were found to be more likely involved in a crash at a location with a grade and/or a curve.

When younger drivers are involved in a crash, Garber and Srinivasan (1991a) found that young drivers are more likely to be cited for exceeding the speed limit as well as the safe speed, following too closely, and inattention. These types of violations reinforce the concerns of risky driving behavior and inexperience among young drivers. For such violations as failing to yield the right-of-way, disregarding the traffic signal, and disregarding the stop or yield sign young drivers are more likely to be cited than middle-age drivers; however, older drivers are more likely to be cited for these violations than young drivers.

Although older drivers are more likely to be cited for failing to yield than young drivers, the possibility of errors in gap estimation and the potential for crashes with a high level of severity among young drivers were the reasons why Kirk and Stamatiadis (2001) studied left-turn crashes among young drivers. Since the only statistically significant finding was the decrease in the involvement ratio with an increase in age, they concluded that risky driving behavior had little effect on left-turning crash rates. Instead, lack of driving experience was the overall contributing factor.

\subsection{Iowa Statistics for Old and Young Drivers}

As discussed, Iowa has a growing population of older drivers. The ratio of older drivers to total population and fatalities per 100,000 older population are higher than the national average, as shown in Table 1.1. 
Table 1.1. Older driver statistics in Iowa

\begin{tabular}{|l|l|l|}
\hline Older Driver Ratios & Iowa & United States \\
\hline $\begin{array}{l}\text { Older Drivers to Total } \\
\text { Population }\end{array}$ & 16.0 & 13.0 \\
\hline $\begin{array}{l}\text { Fatalities per 100,000 older } \\
\text { population }\end{array}$ & 16.5 & 12.2 \\
\hline $\begin{array}{l}\text { Fatalities per 100,000 } \\
\text { licensed drivers }\end{array}$ & 3.6 & 2.3 \\
\hline $\begin{array}{l}\text { Fatalities per 100,000 } \\
\text { registered vehicles }\end{array}$ & 2.2 & 1.9 \\
\hline
\end{tabular}

Source: Toolbox of Highway Safety Strategies (2004)

According to Falb (2004),

- In Iowa (2000), 89 people over age 65 were killed in traffic crashes (20\% of total fatalities).

- Almost 3000 persons (8\% of total injuries) over the age of 65 were injured in traffic crashes.

- The elderly make up a bigger proportion of the fatalities than of the injuries.

Iowa data have also shown that older drivers have a harder time making the left-turn maneuver than younger drivers. Figure 1.3 illustrates the percentage of drivers by age group where one of the circumstances attributed to a particular driver was failure to yield right-of-way (ROW) while making a left turn. As shown, older drivers were much more likely to fail to yield ROW.

Compared to the "average" driver, both older and younger drivers are over-involved in accidents in Iowa. Young drivers are 3.9 times as likely to be involved in a 2-vehicle crash as an average driver based on crashes per VMT by driver age group. They also had a higher rate of involvement than older drivers in Iowa (Naraghi and Souleyrette 2004). Typical crash types in Iowa for young drivers are failure to yield ROW (FTYROW) from stop sign, FTYROW making left turn, ran traffic signal, following too closely, and failure to have control (Naraghi and Souleyrette 2004). They are also more likely to be involved in crashes with more passengers in a vehicle than other age groups, as shown in Figure 1.4. 


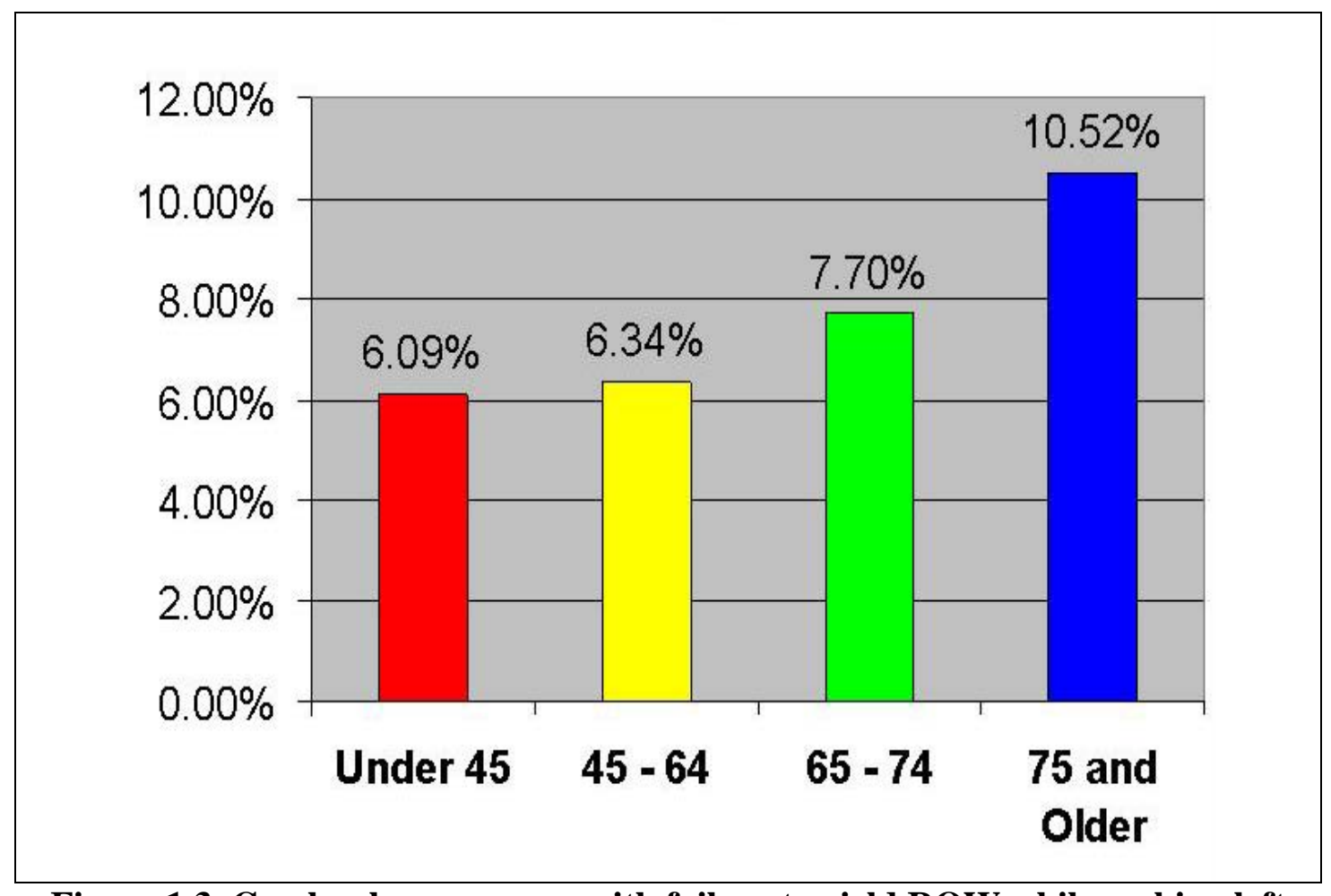

Figure 1.3. Crashes by age group with failure to yield ROW while making left turn (Falb 2004)

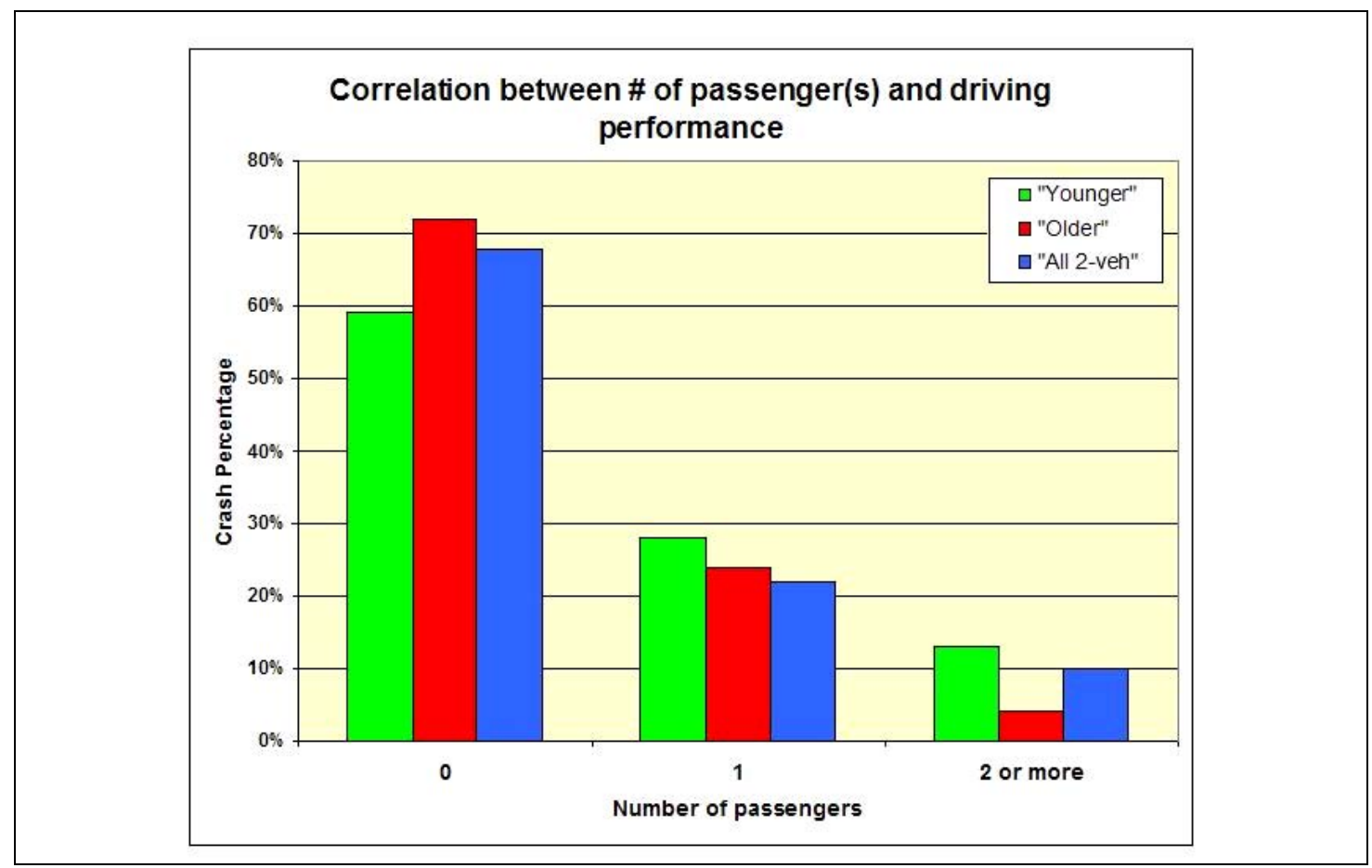

Figure 1.4. Number of passengers in vehicle at time of crash by age group (Naraghi and Souleyrette 2004) 


\subsection{Left-Turn Phasing}

As discussed previously, driver age influences whether a driver is more likely to be involved in a certain type of crash as well as crash likelihood. Research, however, has also shown that the type of left-turn phasing can affect crash rates.

\subsubsection{Safety Performance of Left-Turn Phasing}

Although permitted phasing may increase the capacity of the intersection, as compared to protected phasing, research has shown that protected phasing decreases the number of crashes. Consequently, protected phasing is usually suggested when there are conditions that may lead to an actual or potential left-turn crash problem. Several studies have shown that protected phasing results in the fewest crashes, followed by protected/permitted and then permitted phasing (Maze et al. 1994; Upchurch 1986; and Matthias et al. 1996). Although, there is a permitted phase component in protected/permitted phasing, a lower crash rate than in permitted only phasing occurs because a portion of the left-turning vehicles can make the left turn during the protected phase (Upchurch 1986). The Colorado/Wyoming Section of ITE (1995) also found that protected phasing is safer than the other two phases, but the order depends on the number of left-turn lanes. When one left-turn lane was present, protected phasing was the safest, followed by permitted and then protected/permitted phasing. When two left-turn lanes were present, protected phasing produced the lowest crash rates, followed by protected/permitted and then permitted phasing.

Upchurch (1991) not only compared the safety level between all three types of left-turn phasing, but also distinguished between a leading and lagging left-turn phase for protected and protected/permitted phasing. As a result of the study, Upchurch found the following:

- When there are two opposing lanes, leading protected phasing had the lowest left-turn crash rate, followed by permitted, leading protected/permitted, and lagging protected/permitted phasing.

- When there are three opposing lanes, leading protected phasing had the lowest left-turn crash rate, followed by lagging protected/permitted, permitted, and leading protected/permitted phasing.

- When there are two opposing lanes and the left-turn volume increases, the left-turn crash rate decreases for all four types of phasing; and when there are two opposing lanes and the opposing volume increases, the left-turn crash rate increases for all four types of phasing.

In a study by Warren (1985), control sites were used to determine the impacts on safety when protected/permitted phasing replaced either protected or permitted phasing at high-speed locations with a separate left-turn lane. When protected/permitted phasing replaced protected phasing, the number of total crashes and left-turn crashes increased by about 1.4 and 2 crashes per year, respectively, as compared to the control sites. Both the test and control intersections experienced similar decreases in rear-end accidents. When protected/permitted phasing replaced permitted phasing, the number of left-turn crashes increased by less than one per year per intersection compared to the control intersections, while the number of total and rear-end crashes decreased by approximately 3 crashes per year. 
The safety level at an intersection can be affected not only by the type of left-turn phasing that is present, but also by the presence or absence of a left-turn lane on an approach. When a left-turn lane is present, Maze et al. (1994) found that the left-turn crash rate and the approach crash rate decrease. However, Maze et al. noted that a left-turn lane is usually present when the phasing is protected or protected/permitted. In a study by McCoy and Malone (1989), the presence of leftturn lanes on urban four-lane roadways was found to reduce right angle, rear end, sideswipe, and left-turn crashes at both signalized and uncontrolled approaches.

At signalized intersections, Matthias et al. (1996) found that older drivers are affected by leftturn phasing since they fared better with protected or protected/permitted phasing, and, therefore, protected left-turn phasing with longer clearance intervals could aid older drivers. In addition, signalized intersections, as compared to two-way or four-way stop intersections, present older drivers with a different and perhaps a more difficult set of circumstances since a left-turn maneuver is always made under one of three types of left-turn phasing: protected, protected/permitted, and permitted. Studies have found that protected phasing is the safest since all left turns are made when all conflicting movements are given a red light (Maze, Henderson, and Sankar 1994; Upchurch 1986; Matthias, De Nicholas, and Thomas 1996). For this reason, several studies have concluded that protected phasing should be used when conditions existing under permitted phasing adversely affect safety, such as when the speed limit is greater than 45 mph (Agent 1985; Koupai and Kothari 1999; Upchurch 1986). Consequently, with the concerns over the increase in older drivers, the difficulties older drivers encounter when making left turns, and the influence of the different types of left-turn phasing on safety especially at higher speeds, the purpose of this study was to determine how older drivers are impacted by the three types of left-turn phasing at high-speed intersections, which for this study denotes intersections where at least one roadway has a speed limit of $45 \mathrm{mph}$ or higher on both approaches.

\subsubsection{Left-Turn Phasing Guidelines}

There are three types of left-turn phasing: protected, protected/permitted, and permitted. Under protected-only phasing, left-turning vehicles have the right-of-way. Under permitted-only phasing, all left-turning vehicles must yield to oncoming traffic before turning. The protected/permitted phasing has both a protected and a permitted movement. Currently, there are guidelines, not warrants, for determining when a certain phasing should be used. Guidelines for left-turn phasing can be found in several studies. For example, Agent (1985) conducted a study of 58 intersections in Kentucky where protected/permitted phasing was in place. Agent found that a substantial increase in left-turn crashes occurred when protected/permitted phasing replaced protected phasing and where protected/permitted phasing was in place at approaches with a speed limit greater than $45 \mathrm{mph}$. However, crashes did not significantly increase when protected/permitted phasing replaced permitted phasing. After further analysis, Agent stated that protected/permitted phasing can be used to decrease delay at an intersection, unless certain conditions exist that could produce an increase in crashes, including the following:

1. Speed limit is greater than $45 \mathrm{mph}$.

2. Protected phasing is currently in place and the speed limit is greater than $35 \mathrm{mph}$.

3. There are three or more opposing through lanes.

4. Left-turn lane has a separate signal head due to intersection geometrics. 
5. Dual left-turn lanes are present.

6. Left-turn crash problem is present at the intersection.

7. Potential left-turn crash problem exists.

8. Current sight distance is less than a sight distance based on the speed limit or the 85th percentile speed, a perception-reaction time of 1.5 seconds, and a coefficient of friction of 0.2 .

After surveying a number of agencies, which were mostly located in the United States, to determine the current state of practice on protected/permitted phasing, Koupai and Kothari (1999) recommended that all of the following conditions be satisfied for installation of protected/permitted phasing as long as protected/permitted phasing is not replacing protected phasing:

1. There are more than two vehicles per cycle during the peak hour or when left-turn phasing will be in use.

2. There is only one left-turn lane present, unless there is adequate sight distance for dual left lanes.

3. There are three or less opposing through lanes unless there is a potential crash problem with three opposing through lanes.

4. The speed limit on the opposing approach is $45 \mathrm{mph}$ or less.

5. The critical gap, based on a gap acceptance of 5.5 seconds, is adequate between the left-turn vehicle and the opposing through traffic.

6. The alignment of the left-turn lanes provides a clear view of the opposing traffic.

Additional requirements based on crash experience, delay, volume, or inadequate storage were also given and should be met as well.

Upchurch (1986) created a flow chart, shown in Figure 1.5, to explain when a particular type of phasing should be used for an approach that has a separate left-turn lane, based on a review of warrants, guidelines, and criteria from other agencies as well as a study conducted by Upchurch. The guidelines are based on left-turn demand, number of opposing lanes, volume cross product, opposing speed, sight distance, and left-turn crash history. 


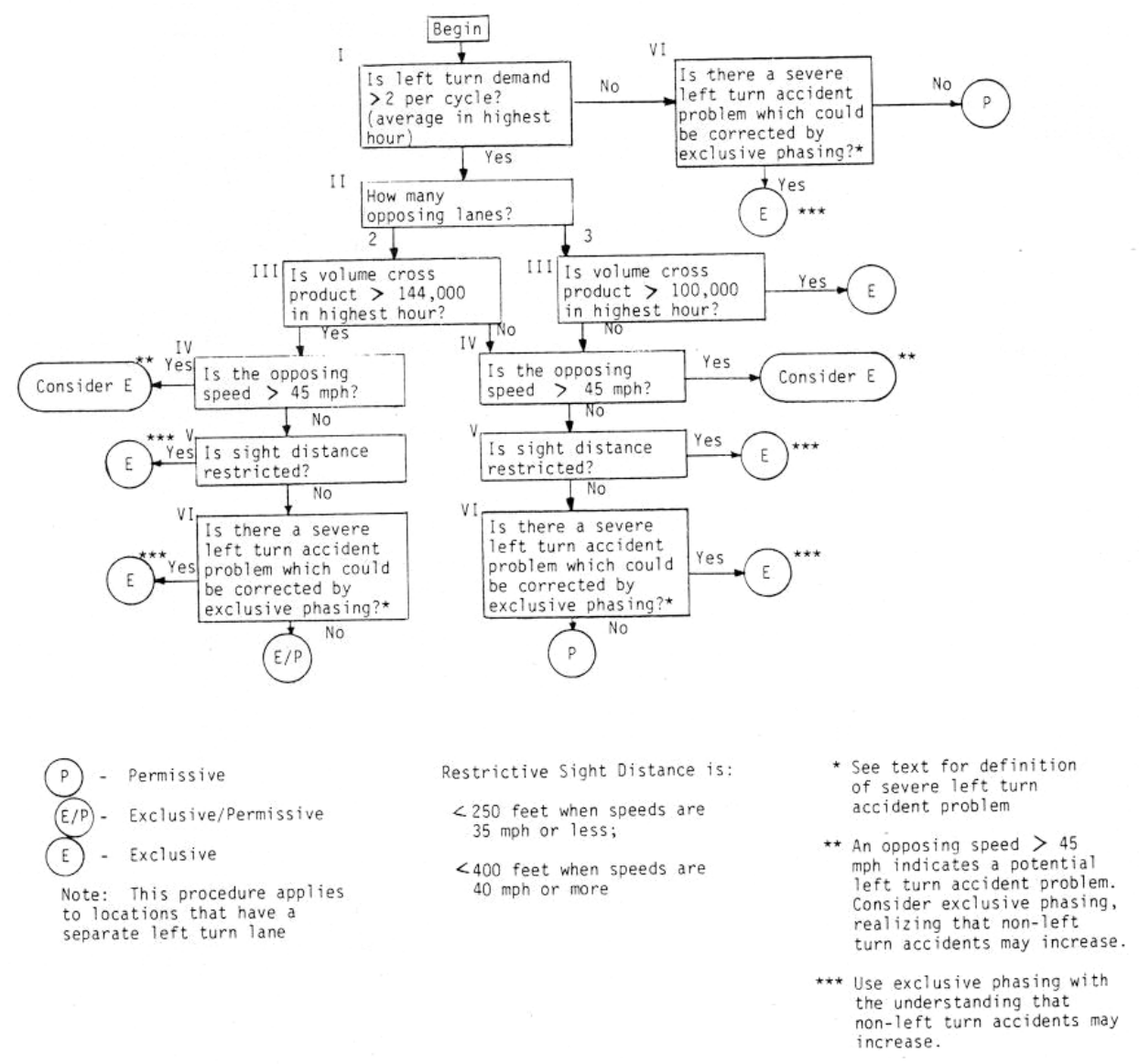

Figure 1.5. Left-turn phase flow chart (Upchurch 1986)

Finally, Cottrell (1986) determined after studying 45 sites that were mostly located on four-lane roads that protected/permitted phasing can be considered when

1. there are few crashes (there are 5 or less annual left-turn crashes, and the critical rate based on an average of 32.6 crashes per 100 million left turns and opposing volume is not exceeded);

2. there are few left-turn conflicts (there are 39 or less conflicts during 4.5 off-peak hours and 2 peak hours, and the total left-turn conflict rate does not exceed critical rate based on a mean of 4 left-turn conflicts per 100 left turns);

3. there are more than two left-turning vehicles per cycle during the peak hour, and the peak hour volume cross product (the left-turn volume multiplied by the opposing through volume) per opposing through lane is between 50,000 and 200,000;

4. there is a long delay for left-turning vehicles (more than 35 vehicles sec/veh and the total peak-hour left-turn delay is greater than 2.0 veh/hour);

5. there is adequate site distance;

6. there are no more than two opposing through lanes;

7. there are no hazardous conditions created by intersection geometry;

8. good access management is present; 
9. all the guidelines are met except the crash guideline, and the delay savings are greater than or equal to the additional crash costs that are incurred when protected/permitted phasing is used instead of protected phasing.

In contrast to the previous studies, Cottrell concluded that safety is not affected by use of protected/permitted phasing at intersections with speed limits of $45 \mathrm{mph}$ or higher, based on a study of four high-speed signalized intersections with protected/permitted phasing.

\subsubsection{Driver Understanding of Left-Turn Control Displays}

Several studies have been conducted to determine driver understanding of different left-turn displays. In these studies, drivers are shown left-turn displays and asked to select the correct response about what the display means. Results indicate that drivers often do not understand the meaning of different types of left-turn displays. They also found that older drivers tend to have the highest incorrect response rate. For younger drivers, the evidence is not so clear. Younger drivers seem to generate a correct response rate similar to middle-age drivers. In one study, Williams et al. (1992) showed drawings of intersections with different left-turn signal displays and auxiliary signs, including some displays which showed a green ball to represent a protected left turn. Higher percentages of incorrect responses—responses that are either inconsistent or wrong - were found among the younger and older age groups. With an incorrect response rate of $35 \%$, drivers older than 65 years of age produced the highest incorrect response rate. The study also found that some of the displays that are currently in use generate a higher percentage of incorrect responses than other displays. For example, under protected/permitted phasing, a green ball or a red ball can be simultaneously lit with the green arrow during the protected phase. In the study, a red ball paired with the green arrow generated a higher percentage of incorrect answers; therefore, the presence of both red and green in a signal head may produce confusion. Similarly, a red arrow or a red ball may be used to prohibit a left-turn movement during protected phasing. The study found that a red arrow produced a higher percentage of incorrect answers when compared to the red ball, which may be a result of the mixed message given by the red arrowthe color red represents stop, while the arrow represents movement.

In another study by Drakopoulos and Lyles (1997), survey participants were shown displays from the 1988 edition of the Manual on Uniform Traffic Control Devices (MUTCD), experimental displays, and nighttime or emergency flashing signal operations. The percentage of correct responses steadily decreased from the youngest age group (71\% for ages $15-30)$ to the oldest age group (50\% for ages 60 and older). The percentage of correct-plus-minor-error response rate followed a similar trend; however, the rate only decreased from $95 \%$ to $90 \%$. This trend shows that older drivers may make conservative choices when they do not understand a left-turn display. Furthermore, when comparing the correct response rate for all drivers, older drivers had lower and statistically different rates for protected, permitted, and flashing signal displays.

Noyce and Kacir $(2001,2002)$ evaluated drivers' understanding of the displays used in protected/permitted phasing exclusively. In the study, display arrangements were shown to study participants, who were asked to choose between four different responses: "GO," "YIELD—wait for gap," "STOP - then wait for gap," and "STOP." For the protected phase, Noyce and Kacir (2002) found that the concurrent illumination of a green arrow and a red ball decreases driver 
understanding and increases the time needed for a driver to make a decision when compared to displays with a green arrow and a green ball or with a green arrow only. This was particularly true for drivers over the age of 65 . This age group had a $62 \%$ correct response rate for the green arrow and red ball display, an 86\% rate for the green arrow and green ball display, and an 89\% rate for the green arrow only display. For the permitted phase, Noyce and Kacir (2001) found that a display with a green ball produced only a 50.4\% correct response rate. If the responses of "YIELD - wait for gap" and "STOP — then wait for gap" were both considered correct, then the correct response rate would rise to 70.5\%. However, the percentage of drivers who responded that the correct action was to turn left without the right-of-way (a critical error) was $24.9 \%$. The study also found that while a green ball was shown for the left-turn movement, a higher percentage of critical errors occurred when a red ball was shown for the through movement compared to when a green ball was shown for the through movement, which may indicate that drivers believed that the opposing approach also had a red ball if the adjacent approach had a red ball. For instance, for the five-section horizontal display, older drivers had the highest critical error rate: $40 \%$ when the through movement had a green ball, as compared to less than $20 \%$ for all other age groups, and 51\% when the through movement had a red ball, as compared to 26.5\% for the 24 to 44 age group. For young drivers, the percentages of correct responses were similar to the percentages for middle-age drivers. 


\section{DATA COLLECTION}

The intent of this study was to evaluate whether older and younger drivers in Iowa are more affected by a particular type of left-turn phasing at high-speed roadways and whether they are more likely to contribute to a left-turn related crash under a specific type of left-turn phasing. High speed was defined as an approach with a posted speed limit of $45 \mathrm{mph}$ or higher. The study evaluated permitted, protected/permitted, and protected left-turn phasing to determine whether a particular type of phasing increased the probability or severity of crashes for young and older drivers. In order to evaluate the likelihood and severity of crashes for a particular type of phasing, the research evaluated left-turn crashes at 101 intersections in Iowa. The following sections describe collection of intersection geometric and operational characteristics and crash data used in the analysis.

The study focused on high-speed signalized intersections. The motivation for the study was to determine whether older or younger drivers experienced more difficulty with a particular type of phasing on high-speed roadways. Left-turn maneuvers under permitted phasing at high-speed locations may be especially problematic for older or younger drivers. Significant oncoming vehicle speeds make it more difficult to judge acceptable gaps for both older drivers, who have lower response times, and younger drivers, who have less experience (FHWA 1993; Staplin 1995; Scialfa et al. 1991; Oxley et al. 2001). Additionally, several studies have indicated that older drivers may have difficulty judging oncoming vehicle speeds (Staplin 1995; FHWA 1993; Scialfa et al. 1991).

\subsection{Selection of Study Locations}

Currently, the State of Iowa does not maintain a statewide intersection database. Two alternate data sets were used to determine possible locations of high-speed signalized intersections. These data sets were the Iowa Department of Transportation (DOT) Geographic Information Management Systems (GIMS) databases and Iowa DOT crash databases. The GIMS database contains information on all public roadways in the state, such as number of lanes, etc. Specific locations of traffic signals are not reported, but the presence or absence of traffic signals along the link is reported. This allowed identification of potential links with signals. The Iowa DOT crash database is statewide and contains information on all reported injury crashes and property damage crashes that occur on public roadways. Data are grouped by year. Crash records include attributes for speed limit and the type of traffic control present, if any of this information was recorded by the police officer.

Intersections were categorized according to whether the GIMS database and/or the crash records indicated an intersection was both high-speed and signalized. After reviewing a number of intersections in each category, it was apparent that the GIMS database and the crash records were not in agreement on the majority of the intersections. This initial list also contained more highspeed signalized intersections than expected for the state of Iowa. In an effort to resolve these discrepancies, the feasibility of using one-meter resolution color infrared (CIR) aerial images to identify signalization was investigated. However, traffic signals could not be detected at this spatial resolution. Using the three sources of data, an initial list of locations that were likely to be high-speed signalized intersections was created. 


\subsection{Selection of Final Test Sites}

After reviewing the potential list of intersections, the study team visited a number of locations or made calls to corresponding city officials to determine whether a signal existed at the location and whether high-speed approaches were present. Intersections at freeway ramps were excluded. Four-approach intersections were only included if one of the intersecting roadways had a speed limit that was $45 \mathrm{mph}$ or higher on both approaches. Several intersections with three approaches were included if one approach with left turns faced an opposing approach that was $45 \mathrm{mph}$ or higher.

Locations were only included if no significant changes had occurred at the intersection. This included geometric changes or changes to the timing plan after June 2000. The study period was from 2001 to 2003. A six-month buffer period before the study period was used since crashes may increase or decrease sharply immediately after a significant improvement and not necessarily reflect long-term conditions. According to Warren (1985), previous research indicated that crashes increased sharply when the left-turn phasing changed from protected to protected/permitted. As drivers adjust to the change in left-turn phasing, there tended to be a reduction in crashes, especially during the first six months. In a study by Stonex and Upchurch (1987), data were collected beginning the seventh month after the left-turn phasing changed. Therefore, a six-month time frame was chosen before collecting crash data to allow drivers to adjust to a change.

A total of 101 intersections met the specified criteria. A list and map of intersection locations are provided in Appendix A and B, respectively. Intersections are located in and around the Des Moines metropolitan area, as well as in the cities of Ames, Marshalltown, Waterloo, Cedar Rapids, Iowa City, North Liberty, and Dubuque.

\subsection{Geometric and Timing Data}

Each study site was visited by the study team to collect geometric characteristics of the intersection, including number and type of lanes, number and placement of signal heads, presence of a left-turn arrow, and type of median. Current traffic signal timing plans were also obtained from the agency that maintains the traffic signals for each study location. Since many traffic signals are currently semi-actuated or fully actuated and timing plans can change throughout the day, only a select number of timing characteristics were included in the study. From the timing plans, the minimum green time, maximum green time, and the clearance interval (yellow and all-red) for the protected left-turn phase were included if a protected leftturn phase existed. In addition, the clearance interval for the through movement was included if permitted left turns are allowed at the intersection.

Agencies were also asked whether any of the intersections had been altered during the study period, and if so, when the alteration occurred. They were asked as to whether a traffic signal had been installed, if the left-turn phasing had changed, and if the intersection geometrics had changed during the study period. 


\subsection{Volume Data}

Traffic counts for the high-speed approaches were obtained from the Iowa DOT traffic count records when available. The state is divided into four quadrants, and each year, the Iowa DOT counts vehicles at select locations in one of the quadrants. As a result, traffic counts are collected in each quadrant every four years. The traffic counts are then converted to annual average daily traffic (AADT) counts. To determine AADT for years when traffic counts were not taken, the Automatic Traffic Recorder Report for each year from 2000 to 2003 was consulted. The Automatic Traffic Recorder Report, which is maintained by the Iowa DOT, gathers volume counts from continuous automatic traffic recorder locations to determine the average statewide change in traffic, which is reported as a percentage, from one year to the next. The changes were very small: a 1\% decrease from 1999 to 2000, a 1\% increase from 2000 to 2001, a 2\% increase from 2001 to 2002, and no change from 2002 to 2003.

In some cases, AADT was not available for all approaches. Alternative sources were then used to determine AADT for the remaining approaches. For a few approaches, AADT maps that were provided by some of the cities were used. The GIMS database was consulted for the other approaches. Counts were normalized to 2001 using an adjustment factor of $1 \%$ per year since a factor of $1 \%$ was the average annual increase reported in the Automatic Traffic Recorder Reports from 1999 to 2003.

\subsection{Crash Data}

Crash data were obtained from the Iowa DOT crash database. Crashes for each intersection were selected for a three-year period from 2001 to 2003. At the start of 2001, a different crash form was used to record crashes than had been used prior to 2001. Because of the transition from one crash report form to another, approximately 9,000 crashes were not included in the 2001 crash database. It was assumed that the omitted crashes were randomly distributed. 


\section{METHODOLOGY}

Left-turn crash rates were developed to compare crash experience for different age groups under the three different types of left-turn phasing considered: protected, protected/permitted, and permitted phasing. A severity index was also calculated to compare the average severity of crashes among the different age groups and types of left-turning phasing. Finally, Poisson regression was used to evaluate such variables as number of opposing lanes and speed limit, which influence crash likelihood. A brief description of each method is presented in the following sections. A more in depth description of the statistical methods and equations used is presented in Appendix C. Analysis and results are presented in section 4.

\subsection{Age Groups}

Drivers were divided into three age groups: young (14- to 24-year-old), middle-age (25- to 64year-old), and older (65+). Smaller age groups such as 14 to 18, 19 to 24, etc. were desirable. Left-turn crashes were evaluated by intersection approach so that left-turn crashes could be allocated to a particular type of phasing. Consequently, only a few crashes were available for any approach and small sample sizes resulted when crashes were divided by age. As a result, the three age groups presented were decided to be the most reasonable.

\subsection{Left-turn Crashes}

Related left-turn crashes were selected from the Iowa DOT crash database for each of the 101 intersections. Related left-turn crashes were defined as those where a driver making a left turn engaged in an action that was the most likely to have contributed to the crash. Possible left-turn crashes included those where a driver was coded as failing to yield right-of-way (FTYROW) while making a left turn, those where the crash type was “angle, oncoming left turn," and headon collisions where one driver was coded as having made an improper turn, etc.

Once all left-turn crashes were selected, a determination was made as to whether the left-turn driver had engaged in an action that was most likely to have contributed to the crash. The Iowa DOT crash database does not include variables that indicate fault. An additional data field is available in which the officer reports the contributing circumstances that resulted in the crash, such as "ran traffic control." This data field was used to determine which driver was more likely to be responsible in a crash. Therefore, the concept of least or most contributing circumstance was used to describe the induced exposure measure rather than "at fault" or "not at fault." For instance, a driver listed with the contributing circumstance of "ran traffic signal” was more likely to have contributed to the crash than the opposing driver who was listed with "exceeded speed limit” as the contributing circumstance.

Only left-turn crashes involving two vehicles were considered in order to facilitate assigning the most serious contributing circumstance. In order to determine which driver contributed the most to a crash, contributing circumstances for each driver from the crash database were compared. In the Iowa crash records, contributing circumstances are listed from the most serious to the least serious with a 1 for the most serious (see Appendix D). In most cases, the driver coded with a lower number for the contributing circumstance was credited with the crash. The actual crash records were consulted if there was a question about what occurred and then credit for the crash was assigned. Crashes where the left-turning driver was not credited with the crash were not 
included since the left-turning driver had not made the most serious error that lead to the crash. Rear-end crashes were also removed because rear-end crashes generally do not result in an inability to determine when a left turn can be made safely. Finally, sideswipe or crashes where the other vehicle was stopped were removed since these crashes usually result from a driver's inability to maintain lane position rather than their ability to interpret and negotiate through the intersection under a particular type of left-turn phasing. Consequently, a total of 117 crashes met the criteria. Relevant left-turn crashes where the left-turning driver contributed the most significant circumstance leading to the crash included those where the left-turning driver made an improper turn, failed to yield the right-of-way, or ran the signal.

Crashes were allocated to the appropriate intersection approach using the "Initial Direction" field from the crash database. The initial travel direction of the vehicle is coded as "East," "West," "North,” or "South.” It was assumed that vehicles that were initially traveling east when making a left turn would be located on the west approach, vehicles initially traveling west before making a left turn were on the east approach, those traveling south were on the north approach, and those traveling north were located on the south approach. Each crash was assigned to an intersection approach based on these criteria.

\subsection{Exposure}

Calculation of crash rate requires the number of crashes for the analysis period in question as well as a measure of exposure. The most common measure of exposure to calculate crash rate is volume. When crash rate for a particular age group, such as fatalities for drivers who are 85year-old and older, is determined, the number of licensed drivers, vehicle miles traveled (VMT), or fraction of the population for that age group are often used as the exposure measure. However, VMT by age group is difficult to obtain on a local or even state level. National studies, such as the National Personal Transportation Study (NPTS), have developed VMT fractions by different age groups. However, national statistics may not be representative of state and local areas. Others have used the number of licensed drivers statewide in each age group (McKelvey and Stamatiais 1989). However, while this provides a measure of the number of potential drivers, this method assumes that all drivers drive an equal amount of miles.

Another method to estimate exposure has been suggested by a number of researchers. A number of studies have used the induced exposure method to estimate the proportion of drivers in a particular category, such as an age group. Using this method, the number of drivers in a particular age group for a particular facility (i.e., specific intersection) can even be determined and used as a measure of exposure. According to Golias and Yannis (2001), the induced exposure method is based on the assumption that in a two-vehicle crash, one driver is responsible for the crash (at-fault) and the second driver, who is not at-fault, is randomly "chosen" from the population of drivers. Since the induced exposure method assumes that the driver who was not at-fault was randomly chosen, the distribution of not at-fault drivers approximates the distribution of all drivers. Therefore, the proportion of drivers in a particular age group or category from the not-at-fault drivers can be multiplied by volume or VMT to provide the measure of exposure for that age group or category of drivers. For instance, if $20 \%$ of the not-atfault drivers were 15- to 20-year-old, they would be assumed to make up $20 \%$ of the on-road volume or VMT. Crash rate for 15- to 20-year-old drivers would be calculated by dividing the number of crashes for that age group by $20 \%$ of the volume. A number of studies have validated 
the induced exposure method. For more information, see Golias and Yannis (2001), Stamatiadis and Deacon (1995), Preusser et al. (1998), and Stamatiadis and Deacon (1997). More information is also provided in Appendix C.

\subsection{Calculation of Exposure by Age Group}

Ideally, a measure of exposure that represents the movement under consideration is used to calculate the crash rate. However, left-turn volumes were not available for all intersections, and project resources were not sufficient to collect left-turn volumes at locations where turning counts were not available. Consequently, volume by approach was used rather than left-turn volumes as the measure of exposure with the assumption that drivers of a particular age group would be equally likely to make a left turn at a particular approach as drivers of another age group. Therefore, the left-turn crash rate for different groups should be comparable within an approach.

Exposure by age group was determined using the induced exposure method. The ratio of drivers for each age group was determined by selecting all two-vehicle crashes within a mile of each study intersection and determining which of the two drivers had the most significant contributing circumstance leading to the crash. The Iowa crash data does not include designation of fault. An attribute that indicates contributing circumstances attributed to an individual driver is available. As discussed in Section 3.2, a determination can be made using this information as to which driver was engaged in the most serious contributing circumstance that lead to the crash.

Hereafter, the driver in a two-vehicle crash who was assigned the most serious contributing circumstances leading to the crash is referred to as the "responsible" driver, or "Driver 1," and the second driver who had less serious contributing circumstances is referred to as the "nonresponsible” driver, or "Driver 2.”

The number of drivers labeled as Driver 2 for all intersections were used to determine the percentage of drivers in each age group. The ratio of drivers by age group was calculated by dividing the number of drivers labeled as Driver 2 in a particular age group by the total number of drivers labeled as Driver 2. A total of 961 two-vehicle crashes were available for the study intersections. Younger drivers (14 to 24) made up 24.1\% of Driver 2 category. Similarly, 67.6\% of drivers in the middle-age group (25 to 64) and 8.2\% in the older driver category (65+) were listed as Driver 2.

Million entering vehicles by approach were determined from AADT estimates, which were discussed in Section 2.4. For each approach, MEV was calculated according to equation (3.1). Since the AADT counts represent two-way volumes, the AADT counts were divided by two, assuming AADT is split evenly between the two approaches.

$$
M E V_{j}=\frac{\left(\frac{A A D T_{k}}{2}\right) * 365}{1,000,000}
$$

where:

$M E V_{j}=$ MEV on the $j^{\text {th }}$ approach

$A A D T_{k}=A D T$ or AADT on selected approach for the $k^{\text {th }}$ year 
The number of entering vehicles for each age group at each approach was then calculated using the ratio of drivers in each age group. $\mathrm{MEV}_{\mathrm{j}}$ was calculated according to the following equation:

$$
M E V_{i j}=M E V_{j} * R_{i}
$$

where:

$$
\begin{aligned}
& M E V_{i j}=\text { million entering vehicles for } i^{\text {th }} \text { age group at the } j^{\text {th }} \text { approach } \\
& M E V_{j}=\text { million entering vehicles for the } j^{\text {th }} \text { approach } \\
& R_{i}=\text { ratio of drivers for the } i^{\text {th }} \text { age group }
\end{aligned}
$$

Crash rates were calculated by summing the number of drivers in left-turn crashes that were labeled as Driver 1 under a certain set of circumstances and dividing by the total MEV for the same set of circumstances, as shown in equation (3.3). For instance, the crash rate for 14- to 24year-old drivers for a particular approach was calculated by dividing the number of left-turn crashes where drivers of that age group were at fault by the MEV for that age group at that approach. Values were adjusted from the 3-year crash analysis period to reflect a yearly crash rate.

where:

$$
\text { CrashRate }=\frac{\text { Crashes }_{i}}{M E V_{i j}}
$$

CrashRate $=$ crash rate per million entering vehicles for age group $i$

Crashes $_{i}=$ number of crashes for age group $i$

$M E V_{i j}=$ million entering vehicles for $i^{\text {th }}$ age group at the $j^{\text {th }}$ approach

\subsection{Severity Rates}

Severity of crashes was also considered. To determine the severity of each crash, the number and type of injuries for each crash were obtained through the Iowa crash database. In the crash database, injuries are classified as fatal, major, minor, possible, or unknown. A severity index was then calculated according to a scale used by the Iowa DOT, as shown in Table 3.1. For each crash, the severity index was calculated by assigning points to each injury type according to the values in Table 3.1. The scale treats possible injuries the same way as unknown injuries. Finally, all crashes received one point for property damage.

Table 3.1. Severity index scale

\begin{tabular}{|l|c|}
\hline Type of Injury or Damage & Points \\
\hline Fatality & 200 \\
\hline Major Injury & 100 \\
\hline Minor Injury & 10 \\
\hline Possible Injury & 1 \\
\hline Unknown Injury & 1 \\
\hline Property Damage & 1 \\
\hline
\end{tabular}




\subsection{Poisson Regression}

Another method that can be used to analyze data is regression analysis. Regression analysis is used to determine the degree of the relationship between several independent variables and a response variable. For this analysis, the response variable was the crash rate, which is the ratio of the number of crashes to the number of entering vehicles. Poisson regression was considered the most appropriate method of analysis since the Poisson distribution describes the probability of rare events occurring based on an infinite number of trials. Since crashes are considered extremely rare events, crashes are often assumed to be Poisson distributed. A description of Poisson Regression is presented in Appendix C.

For this analysis, the response variable was crash rate. The number of crashes was determined for each of the three age groups at each approach, as described in Section 3.4. The independent variables used in the Poisson regression analysis included the following:

- $\quad$ Type of left-turn phasing

- Age group

- Speed limit for opposing approach

- Number of left-turn lanes for the approach analyzed

- Number of through lanes on the opposing approach

- Total number of lanes on the opposing approach

- $\mathrm{ADT}$ on the opposing approach 


\section{RESULTS}

Descriptive statistics were used to describe left-turn crash rates by age group for each type of phasing. Severity by type of left-turn phasing was also calculated. Poisson regression was then used to determine statistical significance of different variables, including type of phasing, on the likelihood of the different age groups being involved in a left-turn crash. Results are presented in the following sections.

\subsection{Left-turn Crash Rates by Type of Phase}

Left-turn crash rates were calculated by age group for each type of left-turn phasing. Crash rates were calculated by dividing the total number of left-turn related crashes by the total number of entering vehicles in millions (MEV) from the selected approaches for each type of phasing using equation (4.1). Calculation of MEV by age group and calculation of crash rate were discussed in Section 3. Results are shown in Table 4.1. As shown, all three age groups have significantly higher crash rates at protected/permitted and permitted than at protected left-turn phasing. Younger drivers (14- to 24-year-old) have a crash rate for permitted that is higher than for protected/permitted. Middle-age drivers (25 to 64) have only marginal differences between protected/permitted and permitted. Older drivers (65+) have a higher crash rate at protected/permitted than at permitted.

where:

$$
\text { CrashRate }_{i j}=\frac{\Sigma \text { Crashes }_{k i j}}{\Sigma M E V_{k i j}}
$$

CrashRate $_{i j}=$ crash rate for phasing type $i$, age group $j$ (crashes/MEV)

Crashes $_{k i j}=$ number of crashes for age group $j$ for approach $k$ with phasing type $i$

$M E V_{k i j} \quad=\mathrm{MEV}$ for age group $j$ for approach $k$ with phasing type $i$

Table 4.1. Left-turn crash rates by type of phasing and by age group

\begin{tabular}{|l|l|l|l|}
\hline \multirow{2}{*}{ Age Group } & Crashes/MEV & \multicolumn{3}{|l|}{} \\
\cline { 2 - 4 } & Protected & Protected/Permitted & Permitted \\
\hline $14-24$ & 0.027 & 0.164 & 0.211 \\
\hline $25-64$ & 0.007 & 0.087 & 0.075 \\
\hline $65+$ & 0.054 & 0.315 & 0.133 \\
\hline
\end{tabular}

\subsection{Severity Index}

The number and type of injuries were extracted from the Iowa DOT crash database for each related left-turn crash for the study intersection approaches. Five types of injuries are coded in the database: fatality, major, minor, possible, and unknown. Possible and unknown injuries carry the same weight in the method that the Iowa DOT uses to assess severity, so possible and unknown injuries were combined for this analysis. For each phasing type, the average number of injuries per crash was calculated according to the type of injury for each type of phasing. Results are shown in Table 4.2. As shown, crashes that occur under protected/permitted phasing result in the most injuries per crash. The number of severe injuries per crash is also higher than the 
average number of severe injuries for the other two types of phasing. The results also indicate that the average number of injuries per crash is just slightly lower for protected phasing than for permitted phasing; however, the injuries tend to be slightly more severe for protected phasing. The average number of injuries according to the type of injury was also calculated for each age group and is shown in Table 4.3. Overall, crashes that were credited to young drivers resulted in the highest number of injuries, followed by older drivers and middle-age drivers. Furthermore, for each type of injury, crashes that were credited to young drivers resulted in the highest number of injuries except for fatal injuries. However, the number of occupants was not considered, so the high rate of injury for younger drivers could have some relationship to the number of occupants present. Out of all left-turn crashes included in this study, only one fatality was reported. This fatality occurred in a crash under protected/permitted phasing and was credited to an older driver.

Table 4.2. Average number and type of injuries per left-turn crash by type of phasing

\begin{tabular}{|l|l|l|l|}
\hline Type of Injury & Protected & Protected/Permitted & Permitted \\
\hline Fatal & 0.00 & 0.01 & 0.00 \\
\hline Major & 0.00 & 0.14 & 0.00 \\
\hline Minor & 0.38 & 0.29 & 0.19 \\
\hline Possible/Unknown & 0.15 & 0.44 & 0.44 \\
\hline Total & 0.54 & 0.89 & 0.63 \\
\hline
\end{tabular}

Table 4.3. Average number and type of injuries per left-turn crash by age group

\begin{tabular}{|l|l|l|l|}
\hline Type of Injury & \multicolumn{1}{|c|}{$\mathbf{1 4 - 2 4}$} & $\mathbf{2 5 - 6 4}$ & $\mathbf{6 5 +}$ \\
\hline Fatal & 0.00 & 0.00 & 0.05 \\
\hline Major & 0.12 & 0.08 & 0.05 \\
\hline Minor & 0.30 & 0.26 & 0.24 \\
\hline Possible/Unknown & 0.60 & 0.25 & 0.43 \\
\hline Total & 1.02 & 0.58 & 0.76 \\
\hline
\end{tabular}

To account for the differences in number and type of injuries among the types of left-turn phasing, a severity index was calculated for each crash by assigning points for each type of injury using the method described in Section 3.5. The average severity per crash was then calculated for each type of left-turn phasing and is shown in Table 4.4. Protected/permitted phasing has the highest average severity index of 21.0. Although crashes under protected phasing have the lowest average number of injuries, protected phasing has the next highest severity index of 5.0 since the crashes tend to be more severe when compared to permitted phasing. Permitted phasing has the lowest index of 3.3 . 
Table 4.4. Average severity for left-turn crashes by type of phasing

\begin{tabular}{|l|c|}
\hline Type of Left-Turn Phasing & Average Severity Index \\
\hline Protected & 5.0 \\
\hline Protected/Permitted & 21.0 \\
\hline Permitted & 3.3 \\
\hline
\end{tabular}

The average severity index was also calculated for each age group, as shown in Table 4.5. Although crashes credited to young drivers had the highest number of injuries per crash, crashes credited to older drivers tended to be the most severe. However, this value may be biased by the fact that the only fatality that occurred was credited to an older driver.

Table 4.5. Average severity by age group

\begin{tabular}{|l|c|}
\hline Age Group & Average Severity Index \\
\hline $14-24$ & 16.3 \\
\hline $25-64$ & 11.4 \\
\hline $65+$ & 18.1 \\
\hline
\end{tabular}

Finally, the average severity index was calculated for each age group according to the type of left-turn phasing. The results in Table 4.6 show that for all age groups, crashes under protected/permitted phasing are the most severe. Overall, young drivers tend to be involved in the most severe crashes under protected and permitted left-turn phasing. Under protected/permitted phasing, older drivers have a slightly higher average severity index than young drivers. It should be noted that a severity index based on the scale shown in Table 4.6 does not take into account the number of passengers. Therefore, if young drivers typically have more passengers in their vehicles, the probability of one or more injuries occurring as a result of a crash increases. Additionally, the fragility of older persons may increase the likelihood of injury occurring.

Table 4.6. Average severity by type of phasing and by age group

\begin{tabular}{|c|c|c|c|}
\hline Age Group & Protected & $\begin{array}{l}\text { Protected/ } \\
\text { Permitted }\end{array}$ & Permitted \\
\hline $14-24$ & 7.0 & 25.6 & 5.0 \\
\hline $25-64$ & 6.3 & 15.8 & 1.9 \\
\hline $65+$ & 1.3 & 26.5 & 1.3 \\
\hline
\end{tabular}




\subsection{Poisson Regression}

Poisson regression was used to model expected crash rate. The response variable was crash rate for a particular age group at each approach modeled. As discussed previously, the crash rate reflected the rate of crash involvement by age group for crashes where the left-turning driver was credited with the most significant contributing circumstance that lead to the crash. The exposure value was MEV for the approach weighted by the proportion of drivers in that age group, as described in Section 3. Each approach of the 101 study intersections that faced an oncoming high-speed approach (45 mph or higher) was modeled separately. A total of 200 approaches met this criterion. Since three age groups were modeled for each approach, a total of 600 samples resulted for the analysis. A crash rate of 0 was used if the approach had no crashes for that age group. A crash was included according to the discussion in the data collection section. As discussed, two-vehicle crashes were included if the most significant contributing circumstance was attributed to the left-turning driver. Crashes that were characterized as a rear-end crash, sideswipe crash, or a crash with a stopped vehicle were not included. The PROC GENMOD procedure in SAS, Release 8.02, was used to create the models.

The independent variables that were considered are listed in Table 4.7. The table shows the range of values used in the analysis and the number of approaches corresponding to a particular value. For instance, 148 approaches have an opposing approach with a speed limit of $45 \mathrm{mph}, 27$ have an opposing approach with a speed limit of $50 \mathrm{mph}$, and 25 have an opposing approach with a speed limit of $55 \mathrm{mph}$. Both age group and type of phasing were considered categorical variables. 
Table 4.7. Independent variables for modeling

\begin{tabular}{|c|c|c|c|}
\hline Independent Variables & Abbreviation & Values & $\begin{array}{l}\text { Number of } \\
\text { Approaches }\end{array}$ \\
\hline \multirow{3}{*}{ Age Group } & \multirow{3}{*}{ Age_grp } & $\begin{array}{ll}0 & \text { (14- to 24-year-olds) } \\
\end{array}$ & \multirow{3}{*}{$\begin{array}{l}\text { All approaches had } \\
\text { observations for } \\
\text { each age group }\end{array}$} \\
\hline & & 1 (25- to 64-year-olds) & \\
\hline & & 2 (65-year-old and older) & \\
\hline \multirow{3}{*}{$\begin{array}{l}\text { Type of } \\
\text { Left-Turn Phasing }\end{array}$} & \multirow{3}{*}{ Phasing } & A (protected) & 88 \\
\hline & & B (protected/permitted) & 69 \\
\hline & & C (permitted) & 43 \\
\hline \multirow{4}{*}{$\begin{array}{l}\text { AADT on Opposing } \\
\text { Approach }\end{array}$} & \multirow{4}{*}{ Opp_adt } & $\begin{array}{ll}0 & (0-4999) \\
\end{array}$ & 42 \\
\hline & & $1 \quad(5000-9999)$ & 99 \\
\hline & & 2 (10000-14999) & 47 \\
\hline & & $3 \quad(15000-19999)$ & 12 \\
\hline \multirow{3}{*}{$\begin{array}{l}\text { Speed Limit on } \\
\text { Opposing Approach } \\
\text { (mph) }\end{array}$} & \multirow{3}{*}{ Opp_spd } & 45 & 148 \\
\hline & & 50 & 27 \\
\hline & & 55 & 25 \\
\hline \multirow{3}{*}{$\begin{array}{l}\text { Number of } \\
\text { Left-Turn Lanes }\end{array}$} & \multirow{3}{*}{ Left } & 0 & 22 \\
\hline & & 1 & 171 \\
\hline & & 2 & 7 \\
\hline \multirow{3}{*}{$\begin{array}{l}\text { Number of Opposing } \\
\text { Through Lanes }\end{array}$} & \multirow{3}{*}{ Opp_thru } & 1 & 19 \\
\hline & & 2 & 157 \\
\hline & & 3 & 24 \\
\hline \multirow{7}{*}{$\begin{array}{l}\text { Total Number of } \\
\text { Opposing Lanes }\end{array}$} & \multirow{7}{*}{ opp_lanes } & 1 & 2 \\
\hline & & 2 & 22 \\
\hline & & 3 & 97 \\
\hline & & 4 & 75 \\
\hline & & 5 & 4 \\
\hline & & $3-10$ & 157 \\
\hline & & $4.0-6.6$ & 157 \\
\hline
\end{tabular}

${ }^{1}$ occurs under protected and protected/permitted phasing only

An in-depth description of how the best model was selected is presented in Appendix C. The best-fit model resulted in inclusion of age group, type of phasing, and AADT of the opposing approach as the relevant independent variables. All three independent variables were found to be significant $(\mathrm{p}<0.0001)$. Model statistics are presented in Table 4.8. 
Table 4.8. Best fit model

\begin{tabular}{|l|l|l|l|l|l|l|l|}
\hline Parameter & DF & Estimate & $\begin{array}{l}\text { Standard } \\
\text { Error }\end{array}$ & \multicolumn{2}{|l|}{$\begin{array}{l}\text { Wald 95\% } \\
\text { Confidence Limits }\end{array}$} & $\begin{array}{l}\text { Wald } \\
\chi^{2}\end{array}$ & Pr $>$ ChiSq \\
\hline Intercept & 1 & -0.8753 & 0.2922 & -1.4481 & -0.3026 & 8.97 & $\mathbf{0 . 0 0 2 7} *$ \\
\hline $\begin{array}{l}\text { Phasing A } \\
\text { (Protected) }\end{array}$ & 1 & -1.6311 & 0.3287 & -2.2753 & -0.9868 & 24.62 & $<\mathbf{0 . 0 0 0 1 *}$ \\
\hline $\begin{array}{l}\text { Phasing B } \\
\text { (protected/per } \\
\text { mitted) }\end{array}$ & 1 & 0.1860 & 0.2168 & -0.2389 & 0.6109 & 0.74 & 0.3910 \\
\hline $\begin{array}{l}\text { Phasing C } \\
\text { (permitted) }\end{array}$ & 0 & 0.0000 & 0.0000 & 0.0000 & 0.0000 & --- & --- \\
\hline $\begin{array}{l}\text { Age_Grp 0 } \\
\text { (14-24) }\end{array}$ & 1 & -0.4454 & 0.2663 & -0.9673 & 0.0766 & 2.80 & 0.0944 \\
\hline $\begin{array}{l}\text { Age_Grp 1 } \\
\text { (25-64) }\end{array}$ & 1 & -1.0823 & 0.2581 & -1.5882 & -0.5765 & 17.59 & $<\mathbf{0 . 0 0 0 1 *}$ \\
\hline $\begin{array}{l}\text { Age_Grp 2 } \\
\text { (65+) }\end{array}$ & 0 & 0.0000 & 0.0000 & 0.0000 & 0.0000 & -- & --- \\
\hline Opp_ADT & 1 & -0.6158 & 0.1397 & -0.8896 & -0.3420 & 19.43 & $<\mathbf{0 . 0 0 0 1 *}$ \\
\hline
\end{tabular}

*meets the alpha level of 0.05

The resulting equation is the following:

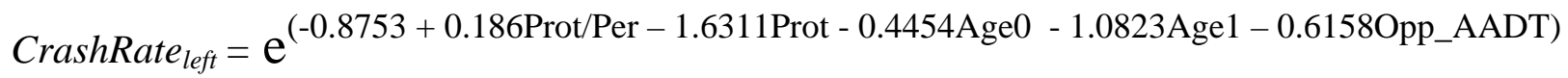

where:

$$
\begin{array}{ll}
\begin{array}{ll}
\text { CrashRate }_{\text {left }}= & \text { left-turn crash rate (crashes/MEV) } \\
\text { Prot/Per } & \text { dummy variable for protected/permitted phasing ( } 0 \text { if phasing is protected } \\
& \text { or permitted, } 1 \text { if phasing is protected/permitted }) \\
= & \text { dummy variable for protected phasing }(0 \text { if phasing is protected/permitted } \\
& \text { or permitted, } 1 \text { if phasing is protected) } \\
\text { Prot } & \text { dummy variable for age group ( } 0 \text { for } 25-64 \text { and } 65+\text { and } 1 \text { for } 14-24) \\
= & \text { dummy variable for age group ( } 0 \text { for } 14-24 \text { and } 65+\text { and } 1 \text { for } 25-64) \\
\text { Age0 } & \text { AADT for opposing approach ( } 1 \text { for AADT from } 5000 \text { to9999; } 2 \text { for } \\
\text { Age } 1 & \text { AADT from } 10000 \text { to } 14999 ; \text { and } 3 \text { for AADT from } 15000 \text { to19999) }
\end{array}
\end{array}
$$

The model indicates that the expected crash rate for protected phasing (A) is lower than for permitted phasing (C). Similarly, the expected crash rate for protected/permitted phasing (B) is higher than for permitted phasing; although, this difference is not statistically significant. To understand how the estimated coefficient describes the relationship between the crash rate and the independent variables, a comparison of the crash rates can be made by dividing the expected crash rate under one set of circumstances by the expected crash rate under a slightly different set of circumstances. If one independent variable increases by one unit while all other variables 
remain constant the ratio simplifies to $e^{\beta i}$. For example, the ratio of the expected crash rate for protected phasing and the expected crash rate for permitted phasing while controlling for the other independent variables is equal to $e^{-1.6311}=0.196$. Therefore, the expected crash rate for protected phasing is $1-0.196$, or $80.4 \%$ lower than the rate for permitted phasing. Similarly, the expected crash rate for protected/permitted phasing is $20.4 \%$ higher than the rate for permitted phasing, and the expected crash rate for protected/permitted phasing is $83.8 \%$ higher than the rate for protected phasing. Using the contrast option in the PROC GENMOD, likelihood ratio tests were calculated to determine if the differences between the three types of left-turn phasing were significant given a significance level of 0.05 . The difference between protected phasing and the other two types of phasing are significant; however, the relationship between protected/permitted phasing and permitted phasing is not significant.

The model also shows that both young drivers (0) and middle-age drivers (1) have an expected crash rate that is less than the rate for older drivers (2) while controlling for all other independent variables in the model. The expected crash rate for young drivers is $35.9 \%$ lower than the rate for older drivers, but this difference is not statistically significant. Middle-age drivers are expected to have a crash rate that is $66.1 \%$ lower than the rate for older drivers and $47.1 \%$ lower than the rate for young drivers. Both of these differences were found to be significant. Finally, opposing ADT was found to be significant. According to the model, for every one level increase in the opposing ADT (an increase of 5,000 vpd), the crash rate decreases by $46.0 \%$.

To examine the differences between all combinations of phasing type and age group, the expected crash rate and confidence intervals were calculated with $\alpha=0.05$. These results are provided in Table 4.9. To calculate the expected crash rate, a value was chosen for the third independent variable, opposing ADT. Since most of the approaches fall in the level 1 category, a comparison was made using the value of 1 for opposing ADT. Therefore, the crash rates listed below are the expected crash rates when the opposing ADT is 5,000 to 9,999 vehicles.

Table 4.9. Expected left-turn crash rates and confidence intervals when the opposing AADT is 5,000 to 9,999 vehicles

\begin{tabular}{|l|l|l|l|l|}
\hline Phasing & Age Group & Expected Crash Rate & \multicolumn{2}{l|}{ Confidence Interval, $\boldsymbol{\alpha}=\mathbf{0 . 0 5}$} \\
\hline \multirow{4}{*}{ Protected } & 14 to 24 & 0.028 & 0.016 & 0.051 \\
\cline { 2 - 5 } & 25 to 64 & 0.015 & 0.009 & 0.026 \\
\cline { 2 - 5 } & $65+$ & 0.044 & 0.023 & 0.085 \\
\hline \multirow{3}{*}{$\begin{array}{l}\text { Protected/ } \\
\text { Permitted }\end{array}$} & 14 to 24 & 0.174 & 0.125 & 0.242 \\
\cline { 2 - 5 } & 25 to 64 & 0.092 & 0.067 & 0.125 \\
\cline { 2 - 5 } & $65+$ & 0.271 & 0.173 & 0.424 \\
\hline \multirow{3}{*}{ Permitted } & 14 to 24 & 0.144 & 0.094 & 0.222 \\
\cline { 2 - 5 } & 25 to 64 & 0.076 & 0.051 & 0.114 \\
\cline { 2 - 5 } & $65+$ & 0.225 & 0.132 & 0.384 \\
\hline
\end{tabular}


Crash rates are statistically different if the two respective confidence intervals do not overlap. It should be noted that the expected crash rate listed in Table 4.9 is determined solely from the best-fit model, which does not consider the interactions between the age groups and the types of phasing. There is some evidence of interaction since the rate for young drivers under permitted phasing is higher than expected after examining the patterns among the other rates. Attempts were made to account for the interaction in the model. However, these attempts did not result in a significantly better model. 


\section{CONSIDERATION OF REAR-END CRASHES UNDER DIFFERENT TYPES OF LEFT-TURN PHASING}

The impact of left-turn phasing on the likelihood of drivers in different age groups to be involved in a left-turn crash for which they contributed the most significant contributing circumstances was evaluated and presented in the previous sections. As discussed, drivers of all age groups are significantly less likely to be involved in left-turn crashes under protected phasing. Drivers for all age groups were also less likely to be involved in crashes under permitted phasing than under protected/permitted phasing. Although protected phasing is the safest phasing for left-turn related crashes, the type of left-turn phasing may impact the likelihood of other crashes as well. Rearend crashes in particular are associated with signalization. Consequently, the impact of different types of phasing on rear-end crashes was evaluated as well.

The number of rear-end crashes was extracted from the 2001 to 2003 crash database for each of the 101 intersection high-speed approaches evaluated for left-turn crash impacts. All rear-end crashes were included whether or not they were related to left-turn phasing since this could not be determined from the crash records. Crashes were allocated to the appropriate intersection approach using the "Initial Direction" field from the crash database, as described in Section 3.2. A large number of rear-end crashes were coded with an "unknown” initial direction for a number of intersections. When a large number of crashes had an unknown direction, the intersection was removed from the analysis. Only high-speed approaches were considered as for the left-turn analysis.

Descriptive statistics were used to describe rear-end crashes by type of phasing. Crash rate for rear-end crashes was calculated by type of left-turn phasing according to equation (5.1).

$$
\text { CrashRate }_{j}=\frac{\Sigma \text { Crashes }_{i j}}{\sum M E V_{k i}}
$$

where:

CrashRate $_{i}=$ crash rate for phasing type $i$ (crashes/MEV)

Crashes $_{k i j}=$ number of crashes for approach $k$ with phasing type $i$

$M E V_{k i j} \quad=$ MEV for approach $k$ with phasing type $i$

A total of 86 high-speed approaches had protected phasing. Seven had 2 left-turn lanes, 3 had no left-turn lane, and the rest had one left-turn lane. Since the majority had one turn lane, a single crash rate was calculated for rear-end crashes with protected left-turn phasing. A total of 61 highspeed approaches had protected/permitted phasing. A single approach did not have a left-turn lane and the rest all had 1 left-turn lane. Consequently, a single crash rate was calculated for all approaches with protected/permitted phasing. A total of 41 high-speed approaches had permitted phasing. Of those, 23 had 1 left-turn lane and 18 had no turn lane. Crash rate was calculated for all approaches with permitted phasing. Separate crash rates were also calculated for approaches with permitted phasing and one left-turn lane and for those with no left-turn lane.

Results are presented in Table 5.1. As shown, approaches with protected phasing have the highest rear end crash rate. Approaches with protected/permitted phasing have the lowest rear end crash rate-more than half that of protected. Approaches with no left-turn lane under permitted phasing have a rear end crash rate that is similar to that of protected. Approaches with 
permitted phasing and one left-turn lane have a rear end crash rate that is similar to approaches with protected/permitted phasing. The rear end crash rate when no left-turn lanes are present is almost twice that when one left-turn lane is present under permitted phasing. Rear-end crashes may be influenced by factors which were not included in this analysis.

Table 5.1. Rear-end crash rate by type of left-turn phasing

\begin{tabular}{|l|r|}
\hline Type of Phasing for Approach & Crash Rate (Crashes/MEV) \\
\hline Protected & 0.17 \\
\hline Protected/Permitted & 0.08 \\
\hline Permitted all approaches & 0.12 \\
\hline Permitted with no left-turn lane & 0.15 \\
\hline Permitted with 1 left-turn lane & 0.09 \\
\hline
\end{tabular}




\section{SUMMARY \& RECOMMENDATIONS}

\subsection{Summary}

Implementation of different types of left-turn phasing is often based on operational considerations. A number of studies, however, have demonstrated differences in safety between different types of left-turn phasing. Several studies have shown that protected phasing results in the lowest crash rate, followed by protected/permitted and then permitted phasing (Maze et al. 1994; Upchurch 1986; and Matthias et al. 1996). Although, there is a permitted phase component in protected/permitted phasing, a lower crash rate than in permitted only phasing occurs because a portion of the left-turning vehicles can make the left turn during the protected phase (Upchurch 1986). The Colorado/Wyoming Section of ITE (1995) also found that protected phasing is safer than the other two phases.

Older drivers are likely to have more problems with left turns than younger drivers. Studies have shown that they are more likely to be involved in angle crashes, more likely to be involved in crashes at intersections, and are cited more often than other age groups for failure to yield rightof-way and illegal or improper turns. Additionally, they have slower perception-reaction times, as well as exhibit more difficulty selecting safe gaps and judging oncoming speeds than younger drivers. There is also evidence that older drivers are less likely to understand the meaning of different types of left-turn displays.

Younger drivers may also have problems with left turns. Lack of experience or risky driving behavior is often cited as reasons for crash involvement among young drivers. When younger drivers are involved in a crash, they are more likely to be cited for exceeding the speed limit, following too closely, and being inattentive. Young drivers are much more likely to be cited for failing to yield the right-of-way, disregarding the traffic signal, and disregarding the stop or yield sign than other age groups.

This study evaluated the impact of different types of left-turn phasing on older and younger drivers at high-speed intersections in Iowa. High-speed intersections were of interest since oncoming speeds and appropriate gaps may be more difficult to judge for older drivers and those with less experience. A total of 101 signalized intersections from various urban locations in Iowa, with at least one intersecting roadway with a posted speed limit of $45 \mathrm{mph}$ or higher, were evaluated. Crash rate and severity for young drivers (14- to 24-year-old), middle-age drivers (25to 64-year-old) and older drivers (65 years and older) were evaluated.

Left-turn related crashes from 2001 to 2003 were evaluated where the left-turning driver contributed the most serious circumstance leading to the crash. The Iowa Department of Transportation (DOT) crash database does not indicate fault. Contributing circumstance in order of severity by driver is recorded. In order to assign the most significant contribution, two-vehicle crashes were used and the driver with the most serious contributing circumstance, such as "ran traffic signal”, was credited with the crash.

The induced exposure method was used to determine crash rate by age group. All two-vehicle crashes within a mile of each intersection were collected. The drivers that were not credited with the crash were treated as a random subset of all drivers. Crash rate was calculated by dividing the 
number of drivers that were credited with a crash in a certain age group by the million entering vehicles (MEV) by approach for that age group.

Poisson regression was used to analyze left-turn crash rates by age group and type of phasing. The left-turn crash rates show that protected phasing is much safer than permitted phasing or protected/permitted phasing ( 0.124 crashes/MEV). Permitted phasing seemed to be just slightly safer than protected/permitted phasing. Crash rates were also calculated by type of phasing and by age group. Again, protected phasing was found to be notably safer than the other two types of phasing. For drivers who are 65-year-old and older, protected/permitted phasing had a higher crash rate than permitted phasing. Permitted phasing had the highest crash rate for young drivers who are 14- to 24-year-old.

Overall, protected/permitted phasing was found to be the least safe, especially for older drivers. The crash rates also show that young and older drivers experience difficulties with permitted phasing. Drivers may have difficulties with both protected/permitted and permitted phasing because left turns can be made during the permitted phase under both types of phasing. Current research reflects the concern over older drivers and the difficulties older drivers experience when judging gaps. For example, many studies have focused on the inability of older drivers to properly judge speeds of oncoming vehicles (Staplin 1995; FHWA 1993; Scialfa et al. 1991). Furthermore, studies have noted that older drivers take longer to execute a left turn (Cox and Cox 1998) and have slower response times (FHWA 1993). Young drivers may experience problems with permitted phasing as well because of their lack of experience and risky driving behavior, which may impact their ability to judge gaps. Lack of driving experience may be more of a contributing factor than risky driving behavior, as stated by Kirk and Stamatiadis (2001). Currently, graduated licensing programs try to help young drivers avoid dangerous situations that stem from lack of experience by placing restrictions on the number of passengers and/or nighttime driving. However, these restrictions may not necessarily reduce left-turn crash rates among young drivers.

It was expected that protected/permitted phasing would have a lower left-turn crash rate than permitted. One reason for the discrepancy may be due to the fact that under low left-turning volumes, the protected phase is not activated, and the phasing basically functions as permitted phasing. Additionally, left-turning volumes were not properly accounted for in the methodology. Permitted/protected phasing may have had significantly higher volumes than permitted. The high crash rate for protected/permitted phasing may also be a reflection of the driver misinterpretation of different protected/permitted phasing signal displays. Several studies had noted that older drivers particularly have difficulty understanding left-turn displays (Williams et al. 1992; Drakopoulous and Lyles 1997; Noyce and Kacir 2002; Noyce and Kacir 2001).

When severity was considered, protected/permitted phasing was found to be the most severe with an average severity index of 21.0. Protected phasing had the next highest severity index of 5.0, while permitted phase had the lowest index of 3.3. When the average severity index was calculated by age groups, protected/permitted phasing again had the highest average severity for all three age groups, especially for young and older drivers. Young and older drivers had an average index of 25.6 and 26.5, respectively, while middle-age drivers had an average index of 15.8. To determine possible reasons why the average severity was much higher for 
protected/permitted phasing, an attempt was made to categorize the crashes to determine if certain types of crashes were more prevalent under one type of phasing compared to another. However, this study considered only one very specific type of left-turn crashes; therefore, it was not possible to further classify the crashes. Furthermore, information such as the type of phase the driver attempted to make a left turn under would be helpful, but it is not available.

\subsection{Recommendations}

Both the crash rates and the average severity index show that protected/permitted phasing is the least safe among the three types of left-turn phasing, especially for older drivers. In contrast, protected phasing is notably safer than protected/permitted and permitted phasing. Although protected phasing results in a slightly higher average severity index than permitted phasing, the crash rates for protected phasing are much lower than the rates for permitted phasing. Therefore, protected phasing is recommended for use at high-speed intersections.

Other studies have recommended adding protected phasing, especially for older drivers. Matthias et al. (1996) found that older drivers are affected by left-turn phasing since they fared better with protected or protected/permitted phasing. Consequently, Matthias et al. state that protected leftturn phasing with longer clearance intervals could aid older drivers. Garber and Srinivason (1991b) also noted that the involvement ratio for older drivers might be reduced by adding protected left-turn phasing. Moreover, they state that the addition of left-turn lanes and an increase in the ratio of amber time to a given speed limit might reduce the involvement ratio as well. Finally, Oxley, Corben, and Fildes (2001) recommend adding fully-controlled right-turn phasing (left-turn phasing in the US) to simplify gap acceptance decisions, as well as replacing stop and yield signs at intersections with signals to decrease the task complexity and using roundabouts.

Many results from this research followed expectations or were similar to results from other studies. One result that was not expected was when the average severity index was found to be much higher for protected/permitted phasing than the severity index for either protected or permitted phasing. Attempts were made to determine possible reasons for this phenomenon. However, more crash data is needed to determine reasons why the severity was much higher for protected/permitted phasing. Therefore, further research on this topic may be a worthwhile effort. 


\section{REFERENCES}

Abdel-Aty, Mohamed A., Chien L. Chen, and A. Essam Radwan. 1999. Using Conditional Probability to Find Driver Age Effect in Crashes. Journal of Transportation Engineering, Vol. 125, No. 6, pp. 502-507.

Agent, Kenneth R. 1985. Guidelines for the Use of Protected/Permissive Left-Turn Phasing. Research Report UKTRP-85-19. Kentucky Transportation Research Program, University of Kentucky, Lexington, Kentucky.

Chandraratna, Susantha, Laura Mitchell and Nikiforos Stamatiadis. 2002. Evaluation of the Transportation Safety Needs of Older Drivers. Department of Civil Engineering, University of Kentucky, Lexington, Kentucky.

Colorado/Wyoming Section-ITE. 1995. Permissive Double Left Turns: Are They Safe? 1995 Compendium of Technical Papers, Institute of Transportation Engineers $65^{\text {th }}$ Annual Meeting, Denver, Colorado.

Cottrell Jr., Benjamin H. 1986. Guidelines for Protected/Permissive Left-Turn Signal Phasing. Transportation Research Record 1069, TRB, National Research Council, Washington, D.C., pp. 54-61.

Cox, Amanda B., and Daniel J. Cox. 1998. Compensatory Driving Strategy of Older People May Increase Driving Risk. Journal of the American Geriatrics Society, Vol. 46, No. 8, pp. 10581059.

Dissanayake, Sunanda, Jian John Lu, Xuehao Chu and Patricia Turner. 1999. Evaluation of Critical Highway Safety Needs of Special Population Groups. ITE Journal, Vol. 69, No. 9, pp. 28-35.

Drakopoulos, Aris, and Richard W. Lyles. 1997. Driver Age as a Factor in Comprehension of Left-Turn Signals. Transportation Research Record 1573, TRB, National Research Council, Washington, D.C., pp. 76-85.

Falb, Scott R. 2004. Left Behind: Transportation Problems of the Elderly Living in Disappearing Rural Communities. 30th International Traffic Records Forum. Nashville, TN.

Federal Highway Administration. 1997. Statistical Models of Accidents on Interchange Ramps and Speed-Change Lanes. Report FHWA-RD-97-106. US Department of Transportation, Washington D.C.

Federal Highway Administration. 1995. Traffic Operations Control for Older Drivers. Report FHWA-RD-94-119. US Department of Transportation, Washington D.C.

Federal Highway Administration. 1993. Traffic Maneuver Problems of Older Drivers: Final Technical Report. Report FHWA-RD-92-092. US Department of Transportation, Washington D.C. 
Garber, Nicholas J., and Raghavan Srinivasan. 1991a. Characteristics of Accidents Involving Elderly Drivers at Intersections. Transportation Research Record 1325, TRB, National Research Council, Washington, D.C., pp. 8-16.

Garber, Nicholas J., and Raghavan Srinivasan. 1991b. Risk Assessment of Elderly Drivers at Intersections: Statistical Modeling. Transportation Research Record 1325, TRB, National Research Council, Washington, D.C., pp. 17-22.

Golias, John, and George Yannis. 2001. Dealing with Lack of Exposure Data in Road Accident Analysis. Traffic Safety on Three Continents Conference, Moscow, Russia.

Hauer, Ezra. 2001. Computing and Interpreting Accident Rates for Vehicle Types or Driver Groups. Transportation Research Record 1746, TRB, National Research Council, Washington D.C., pp. 69-73.

Kirk, Adam, and Nikiforos Stamatiadis. 2001. Crash Rates and Traffic Maneuvers of Younger Drivers. Transportation Research Record 1779, TRB, National Research Council, Washington, D.C., pp. 68-74.

Koupai, Parviz A., and Amit M. Kothari. 1999. Recommended Guidelines for Protected/Permissive Left-Turn Phasing. Transportation Frontiers for the Next Millennium: $69^{\text {th }}$ Annual Meeting of the Institute of Transportation Engineers, Las Vegas, Nevada.

Long, Paul R. 1996. Population Projections for States by Age, Sex, Race, and Hispanic Origin: 1995 to 2025. U.S. Bureau of the Census, Population Division, PPL-47.

Li, Guohua, Elisa R. Braver, Li-Hui Chen. 2003. Fragility Versus Excessive Crash Involvement as Determinants of High Death Rates per Vehicle-Mile of Travel Among Older Drivers. Accident Analysis and Prevention, Vol. 35, No. 2, pp. 227-235.

Matthias, Judson D., Maralou E. De Nicholas, and Gary B. Thomas. 1996. A Study of the Relationship Between Left Turn Accidents and Driver Age in Arizona. AZ - SP - 9603, Arizona Department of Transportation, Phoenix, Arizona.

Maze, Tom H., Joseph L. Henderson, and Raji Sankar. 1994. Impacts on Safety of Left-Turn Treatment at High Speed Signalized Intersections. Iowa Highway Research Board, Project HR 347, Iowa Transportation Center, Iowa State University, Ames, Iowa.

McCoy, Patrick T., and Michael S. Malone. 1989. Safety Effects of Left-Turn Lanes on Urban Four-Lane Roadways. Transportation Research Record 1239, TRB, National Research Council, Washington, D.C., pp. 17-22.

McKelvey, Francis X. and Nikiforos Stamatiadis. 1989. Highway Accident Patterns in Michigan Related to Older Drivers. Transportation Research Record 1210, TRB, National Research Council, Washington, D.C., pp. 53-57. 
Mercier, Cletus R., Mack C. Shelley II, Geneva H. Adkins, and Joyce M. Mercier. 1999. Age and Gender as Predictors of Injury Severity in Broadside and Angle Vehicular Collisions. Transportation Research Record 1693, TRB, National Research Council, Washington, D.C., pp. 50-61.

Naraghi, Hussein and Reg Souleyrette. 2004. Investigating Crash Interaction of Younger and Older Drivers. 30th International Traffic Records Forum. Nashville, TN.

National Highway Traffic Safety Administration. 2002a. Traffic Safety Facts 2002 - Older Population. DOT HS 809611.

National Highway Traffic Safety Administration. 2002b. Traffic Safety Facts 2002 - Young Drivers. DOT HS 809619.

National Highway Traffic Safety Administration. 2000. Older Driver Fatality Rates by States. Research Note.

Noyce, David A., and Kent C. Kacir. 2001. Driver Understanding of Simultaneous Traffic Signal Indications in Protected Left Turns. Transportation Research Record 1754, TRB, National Research Council, Washington, D.C., pp. 18-26.

Noyce, David A. and Kent C. Kacir. 2001. Drivers’ Understanding of Protected-Permitted LeftTurn Signal Displays. Transportation Research Record 1754, TRB, National Research Council, Washington, D.C., pp. 1-10.

Oxley, Jennifer, Bruce Corben, and Brian Fildes. 2001. Older Driver Highway Design: The Development of a Handbook and Training Workshop to Design Safe Road Environments for Older Drivers. Traffic Safety on Three Continents Conference, Moscow, Russia.

Preusser, David F., Allan F. Williams, Susan A. Ferguson, Robert G. Ulmer, and Helen B. Weinstein. 1998. Fatal Crash Risk for Older Drivers at Intersections. Accident Analysis and Prevention, Vol. 30, No. 2, pp. 151-159.

Safety Management Toolbox. 2004. Iowa Highway Safety Management System. http://www.iowasms.org/toolbox.htm.

Scialfa, Charles T., Lawrence T. Guzy, Herschel W. Leibowitz, Philip M. Garvey, and Richard A. Tyrrell. 1991. Age Differences in Estimating Vehicle Velocity. Psychology and Aging, Vol. 6, No. 1, pp. 60-66.

Stamatiadis, Nikiforos and John A. Deacon. 1997. Quasi-Induced Exposure: Methodology and Insight. Accident Analysis and Prevention, Vol. 29, No. 1, pp. 37-52. 
Stamatiadis, Nikiforos and John A. Deacon. 1995. Trends in Highway Safety: Effects of an Aging Population on Accident Propensity. Accident Analysis and Prevention, Vol. 27, No. 4, pp. 443-459.

Stamatiadis, Nikiforos, William C. Taylor, and Francis X. McKelvey. 1991. Elderly Drivers and Intersection Accidents. Transportation Quarterly, Vol. 45, No. 3, pp. 377-390.

Staplin, Loren. 1995. Simulator and Field Measures of Driver Age Differences in Left-Turn Gap Judgments. Transportation Research Record 1485, TRB, National Research Council, Washington, D.C., pp. 49-55.

Stonex, Anne and Jonathan E. Upchurch. 1987. Conversion from Permissive to Exclusive/Permissive Left-Turn Phasing: A Before-and-After Evaluation. Transportation Research Record 1114, TRB, National Research Council, Washington, D.C., pp. 63-73.

Upchurch, Jonathan E. 1991. Comparison of Left-Turn Accident Rates for Different Types of Left-Turn Phasing. Transportation Research Record 1324, TRB, National Research Council, Washington, D.C., pp. 33-40.

Upchurch, Jonathan E. 1986. Guidelines for Selecting Type of Left-Turn Phasing. Transportation Research Record 1069, TRB, National Research Council, Washington, D.C., pp. 30-38.

Warren, Davey L. 1985. Accident Analysis of Left-Turn Phasing. Public Roads, Vol. 48, No. 4, pp. 121-127.

Williams, James C., Siamak A. Ardekani, and Seth Adu Asante. 1992. Motorist Understanding of Left-Turn Signal Indications and Auxiliary Signs. Transportation Research Record 1376, TRB, National Research Council, Washington, D.C., pp. 57-63. 


\section{APPENDIX A: LIST OF INTERSECTION LOCATIONS}

\begin{tabular}{|c|c|c|c|c|c|}
\hline \multirow{2}{*}{ CO_NAME } & \multirow{2}{*}{ CITY_NAME } & \multirow{2}{*}{ LIT_DESC } & \multicolumn{3}{|c|}{ NO. OF APPROACHES } \\
\hline & & & PROT & $\mathrm{P} / \mathrm{P}$ & PERM \\
\hline POLK & ALTOONA & 8TH ST SW \& 34TH AVE/NE 56TH ST & & 2 & \\
\hline POLK & ALTOONA & 8TH ST SW \& 17TH AVE SW/NE 64TH ST & & 2 & \\
\hline POLK & ALTOONA & 8TH ST SW \& 36TH AVE & & 2 & \\
\hline POLK & ALTOONA & 8TH ST SW \& 8TH CT SW/SCENIC VIEW BLVD & & 2 & \\
\hline POLK & ALTOONA & US 6 (HUBBELL AVE) \& ADVENTURELAND DR/9TH ST NW & 2 & & \\
\hline POLK & ALTOONA & US 6 (HUBBELL AVE) \& NE 46TH AVE & 2 & & 2 \\
\hline STORY & AMES & US 69 (S DUFF AVE) \& BILLY SUNDAY RD/AIRPORT RD & & 2 & \\
\hline STORY & AMES & US 69 (GRAND AVE) \& BLOOMINGTON RD/FRONTAGE RD & & 2 & \\
\hline STORY & AMES & ELWOOD DR \& MORTENSEN PKWY & & 1 & \\
\hline STORY & AMES & DAYTON AVE \& 13TH ST & & 2 & \\
\hline STORY & AMES & ELWOOD DR \& S 16TH ST/PARKING LOT ENT & & 2 & \\
\hline POLK & ANKENY & IA 160 (ORALABOR RD) \& US 69 (S ANKENY BLVD) & 4 & & \\
\hline POLK & ANKENY & US 69 (S ANKENY BLVD) \& MAGAZINE ROAD & & 1 & 1 \\
\hline POLK & ANKENY & IA 160 (ORALABOR RD) \& IA 415 (SW STATE ST) & 4 & & \\
\hline POLK & ANKENY & IA 160 (ORALABOR RD) \& SE DELAWARE AVE & 2 & & \\
\hline POLK & ANKENY & IA 160 (ORALABOR RD) \& SW IRVINEDALE DR/SW 28TH ST & & 2 & \\
\hline LINN & CEDAR RAPIDS & IA 100 (COLLINS AVE) \& COUNCIL ST & 2 & & \\
\hline LINN & CEDAR RAPIDS & IA 100 (COLLINS AVE) \& ROCKWELL DR & & 1 & \\
\hline LINN & CEDAR RAPIDS & 16TH AVE SW \& WEST POST RD & & & 2 \\
\hline LINN & CEDAR RAPIDS & 16TH AVE SW \& WILEY BLVD & & & 2 \\
\hline LINN & CEDAR RAPIDS & EDGEWOOD RD \& ELLIS RD & & 2 & \\
\hline LINN & CEDAR RAPIDS & EDGEWOOD RD \& GLASS RD & & 1 & \\
\hline LINN & CEDAR RAPIDS & EDGEWOOD RD \& 42ND ST & & 2 & \\
\hline POLK & DES MOINES & IA $28 \&$ PARK AVE & 1 & & \\
\hline POLK & DES MOINES & ARMY POST RD \& INDIANOLA AVE & & 2 & \\
\hline DUBUQUE & DUBUQUE & US 20 (DODGE ST) \& MIDWAY ENTRANCE & 1 & & \\
\hline DUBUQUE & DUBUQUE & US 20 (DODGE ST) \& NORTHWEST ARTERIAL & 2 & & \\
\hline DUBUQUE & DUBUQUE & US 20 (DODGE ST) \& CENTURY DR & 2 & & \\
\hline DUBUQUE & DUBUQUE & US 20 (DODGE ST) \& CEDAR CROSS RD & 2 & & \\
\hline DUBUQUE & DUBUQUE & US 20 (DODGE ST) \& WACKER DR & 2 & & \\
\hline DUBUQUE & DUBUQUE & US 20 (DODGE ST) \& DEVON DR & 2 & & \\
\hline DUBUQUE & DUBUQUE & US 20 (DODGE ST) \& CRESCENT RIDGE & 2 & & \\
\hline DUBUQUE & DUBUQUE & US 20 (DODGE ST) \& OLD HIGHWAY RD & & & 2 \\
\hline DUBUQUE & DUBUQUE & NORTHWEST ARTERIAL \& PENNSLYVANIA AVE & 2 & & \\
\hline DUBUQUE & DUBUQUE & NORTHWEST ARTERIAL \& ASBURY RD & & 2 & \\
\hline DUBUQUE & DUBUQUE & NORTHWEST ARTERIAL \& CHAVENELLE DR & & 2 & \\
\hline DUBUQUE & DUBUQUE & US 151 (US 61) \& JONES ST & 2 & & \\
\hline DUBUQUE & DUBUQUE & US 151 (US 61) \& LOCUST CONNECTOR & 1 & & \\
\hline DUBUQUE & DUBUQUE & US 151 (US 61) \& US 52/TWIN VALLEY DR & & 2 & \\
\hline
\end{tabular}




\begin{tabular}{|c|c|c|c|c|c|}
\hline DUBUQUE & DUBUQUE & US 151 (US 61) \& MAQUOKETA DR & 2 & & \\
\hline DALLAS & GRANGER & IA $141 \&$ F31 & & 2 & \\
\hline POLK & GRIMES & IA $141 \&$ NW 54TH AVE & 2 & & \\
\hline JOHNSON & IOWA CITY & IA $1 \&$ WESTPORT PLAZA & 1 & & \\
\hline JOHNSON & IOWA CITY & IA 1 \& NCS PEARSON ENTRANCE & 2 & & \\
\hline JOHNSON & IOWA CITY & IA $1 \&$ SUNSET ST & 2 & & \\
\hline JOHNSON & IOWA CITY & IA 6 \& FAIRMEADOWS BLVD & 1 & & 1 \\
\hline JOHNSON & IOWA CITY & IA 6 \& INDUSTRIAL PARK RD/LAKESIDE DR & 2 & & \\
\hline MARSHALL & MARSHALLTOWN & CENTER ST \& BERLE RD & & & 2 \\
\hline MARSHALL & MARSHALLTOWN & CENTER ST \& IOWA AVE & & 2 & \\
\hline MARSHALL & MARSHALLTOWN & CENTER ST \& MERLE HIBBS BLVD & & & 2 \\
\hline JOHNSON & NORTH LIBERTY & IA 965 \& WESTWOOD DR & & & 2 \\
\hline JOHNSON & NORTH LIBERTY & IA 965 \& ZELLER ST & & & 2 \\
\hline JOHNSON & NORTH LIBERTY & IA 965 \& PENN ST & & & 2 \\
\hline POLK & PLEASANT HILL & IA 163 \& NE 80TH ST & & & 2 \\
\hline POLK & PLEASANT HILL & IA 163 \& HICKORY BLVD & 2 & & \\
\hline POLK & PLEASANT HILL & IA 163 \& NE 56TH ST & 2 & & \\
\hline POLK & URBANDALE & DOUGLAS AVE \& 83RD ST & 2 & & \\
\hline POLK & URBANDALE & DOUGLAS AVE \& MARY LYNN DR & 2 & & \\
\hline POLK & URBANDALE & DOUGLAS AVE \& 86TH ST & 2 & & \\
\hline POLK & URBANDALE & US 6 (HICKMAN RD) \& NW 111TH ST & 2 & & \\
\hline POLK & URBANDALE & US 6 (HICKMAN RD) \& NW 104TH ST/FRONTAGE RD & 2 & & \\
\hline POLK & URBANDALE & MERLE HAY RD \& SUTTON DR/FRONTAGE RD & 2 & & \\
\hline BLACKHAWK & WATERLOO & GREENHILL RD \& KATOSKI DR & & 1 & \\
\hline BLACKHAWK & WATERLOO & GREENHILL RD \& MAYNARD AVE & & 2 & \\
\hline BLACKHAWK & WATERLOO & GREENHILL RD \& RAINBOW DR & & 2 & \\
\hline BLACKHAWK & WATERLOO & KATOSKI DR \& DOWNING AVE & & 2 & \\
\hline BLACKHAWK & WATERLOO & UNIVERSITY AVE \& HOLIDAY STATION & & 2 & \\
\hline BLACKHAWK & WATERLOO & UNIVERSITY AVE \& MIDWAY DR & & 2 & \\
\hline BLACKHAWK & WATERLOO & UNIVERSITY AVE \& PROGRESS AVE & & 2 & \\
\hline BLACKHAWK & WATERLOO & UNIVERSITY AVE \& K-MART & 2 & & \\
\hline BLACKHAWK & WATERLOO & UNIVERSITY AVE \& FALLS AVE & 2 & & \\
\hline BLACKHAWK & WATERLOO & UNIVERSITY AVE \& SAGER AVE & & 2 & \\
\hline BLACKHAWK & WATERLOO & UNIVERSITY AVE \& WALLGATE AVE & & & 2 \\
\hline BLACKHAWK & WATERLOO & UNIVERSITY AVE \& FLETCHER AVE & & 2 & \\
\hline BLACKHAWK & WATERLOO & UNIVERSITY AVE \& ANSBOROUGH AVE & & 2 & \\
\hline BLACKHAWK & WATERLOO & SERGEANT RD \& FLETCHER AVE & & & 2 \\
\hline BLACKHAWK & WATERLOO & SERGEANT RD \& ANSBOROUGH AVE & 2 & & \\
\hline BLACKHAWK & WATERLOO & SERGEANT RD \& RIDGEWAY AVE & & 4 & \\
\hline BLACKHAWK & WATERLOO & SERGEANT RD \& W 3RD ST & 2 & & \\
\hline BLACKHAWK & WATERLOO & RIDGEWAY AVE \& DEERE RD & & 1 & \\
\hline BLACKHAWK & WATERLOO & BROADWAY ST \& DONALD ST & 2 & & \\
\hline BLACKHAWK & WATERLOO & BROADWAY ST \& CEDAR BEND ST & & & 1 \\
\hline BLACKHAWK & WATERLOO & BROADWAY ST \& BURTON AVE & & & 2 \\
\hline
\end{tabular}




\begin{tabular}{|c|c|c|c|c|c|}
\hline BLACKHAWK & WATERLOO & BROADWAY ST \& WAGNER RD & 2 & & \\
\hline BLACKHAWK & WATERLOO & US 63 (LOGAN AVE) \& AIRLINE HWY & 2 & & 2 \\
\hline BLACKHAWK & WATERLOO & DUBUQUE RD \& ADRIAN ST & & & 2 \\
\hline BLACKHAWK & WATERLOO & I 380/US 218 \& MITCHELL AVE & 2 & & \\
\hline BLACKHAWK & WATERLOO & US 218 (WASHINGTON ST) \& HAWTHORNE AVE & & 2 & \\
\hline BLACKHAWK & WATERLOO & US 218 (WASHINGTON ST) \& SHAULIS RD & 2 & & \\
\hline BLACKHAWK & WATERLOO & W SAN MARNAN DR \& ANSBOROUGH AVE & 2 & & \\
\hline BLACKHAWK & WATERLOO & W SAN MARNAN DR \& KIMBALL AVE & & 2 & \\
\hline BLACKHAWK & WATERLOO & W SAN MARNAN DR \& SHOPPER'S BLVD & & 1 & \\
\hline BLACKHAWK & WATERLOO & IA 21 (HAWKEYE RD) \& SAN MARNAN DR & 1 & & \\
\hline BLACKHAWK & WATERLOO & IA 21 (HAWKEYE RD) \& ORANGE RD & & & 4 \\
\hline POLK & & US 69 (NE 14TH ST) \& NE 51ST AVE & & 1 & 1 \\
\hline POLK & & US 69 (NE 14TH ST) \& NE 58TH AVE & & & 1 \\
\hline POLK & & US 69 (NE 14TH ST) \& NE 66TH AVE & 2 & & \\
\hline POLK & & IA 415 (2ND ST) \& NW 54TH AVE & & & 2 \\
\hline POLK & & US 69 (NE 14TH ST) \& NE 46TH AVE (NE BROADWAY AVE) & 2 & & \\
\hline POLK & & IA 415 (2ND AVE) \& NE 46TH AVE (NW BROADWAY AVE) & & 1 & \\
\hline POLK & & IA 415 (NW 2ND ST) \& NW 47TH PL/NW 48TH PL & & & 2 \\
\hline
\end{tabular}




\section{APPENDIX B: LOCATION OF HIGH-SPEED INTERSECTIONS}

Locations are shown by city.
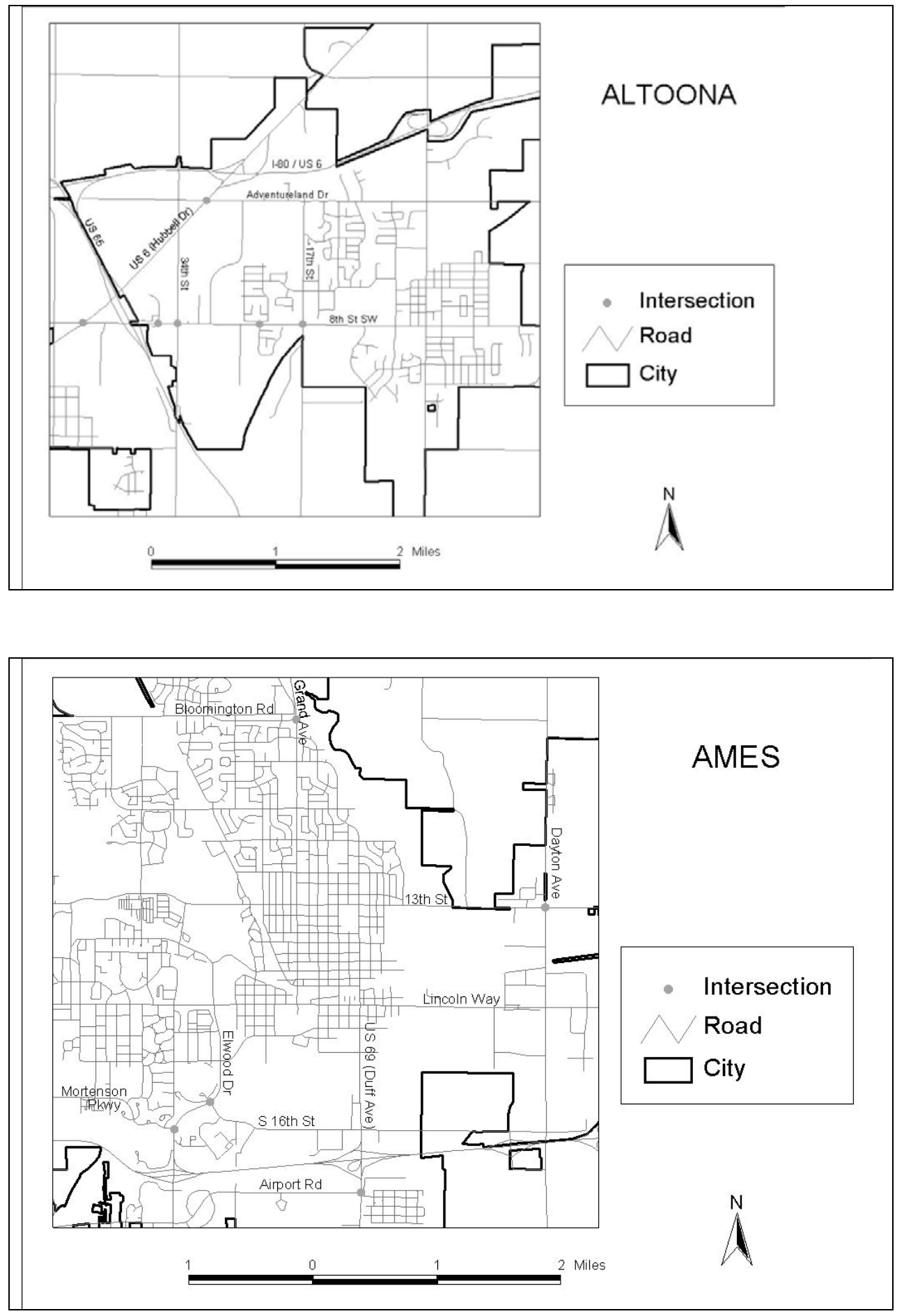

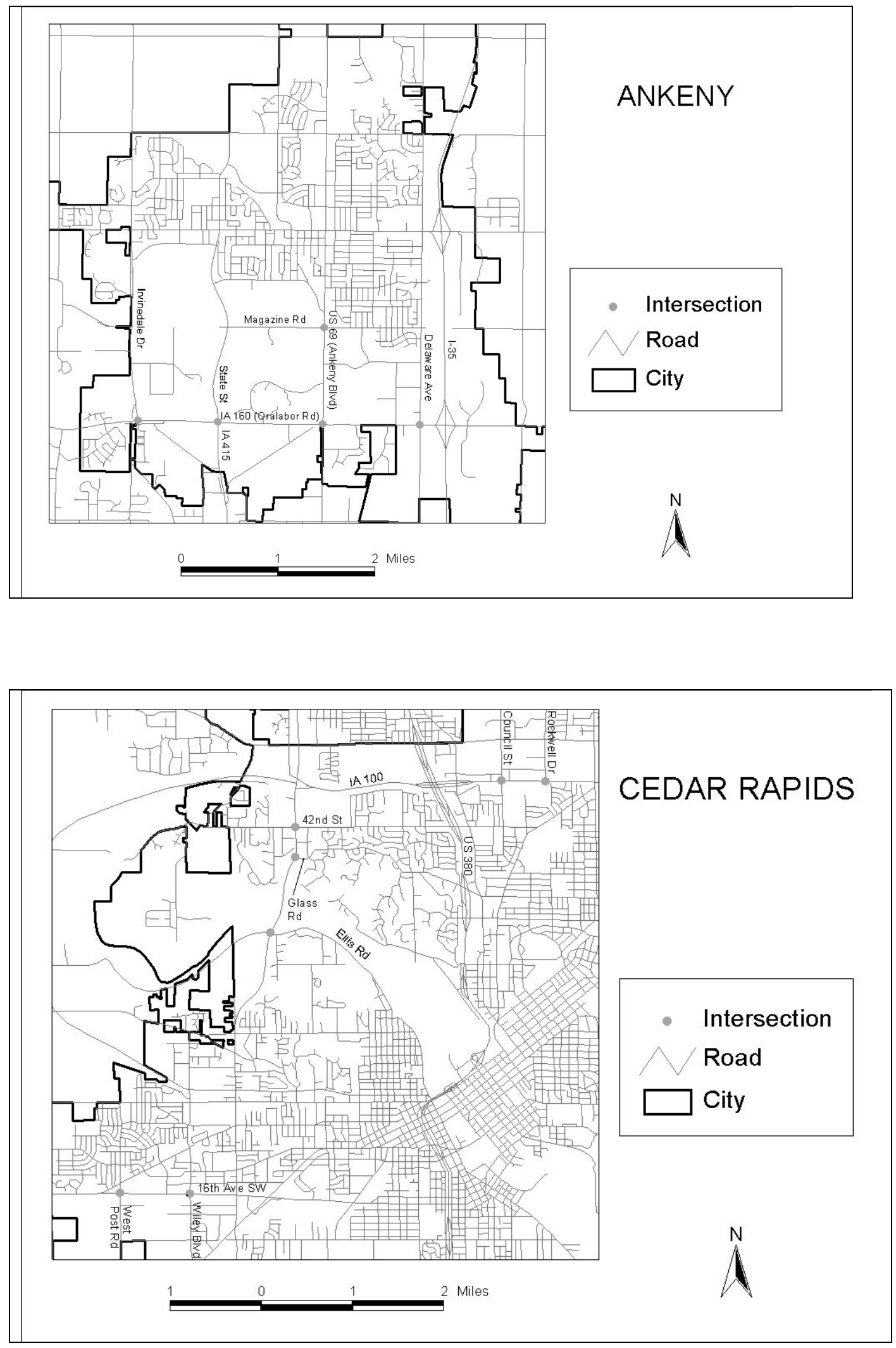

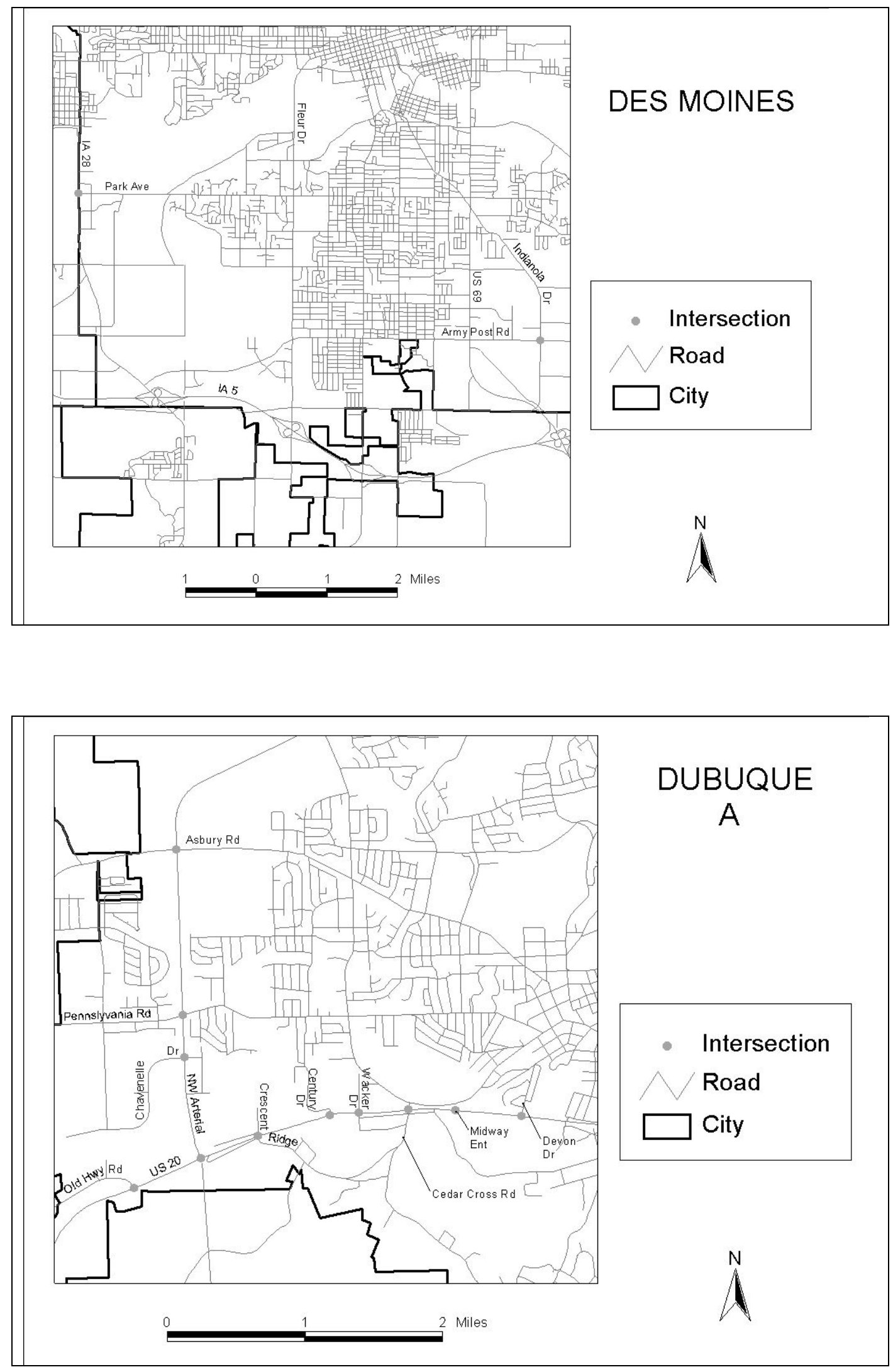

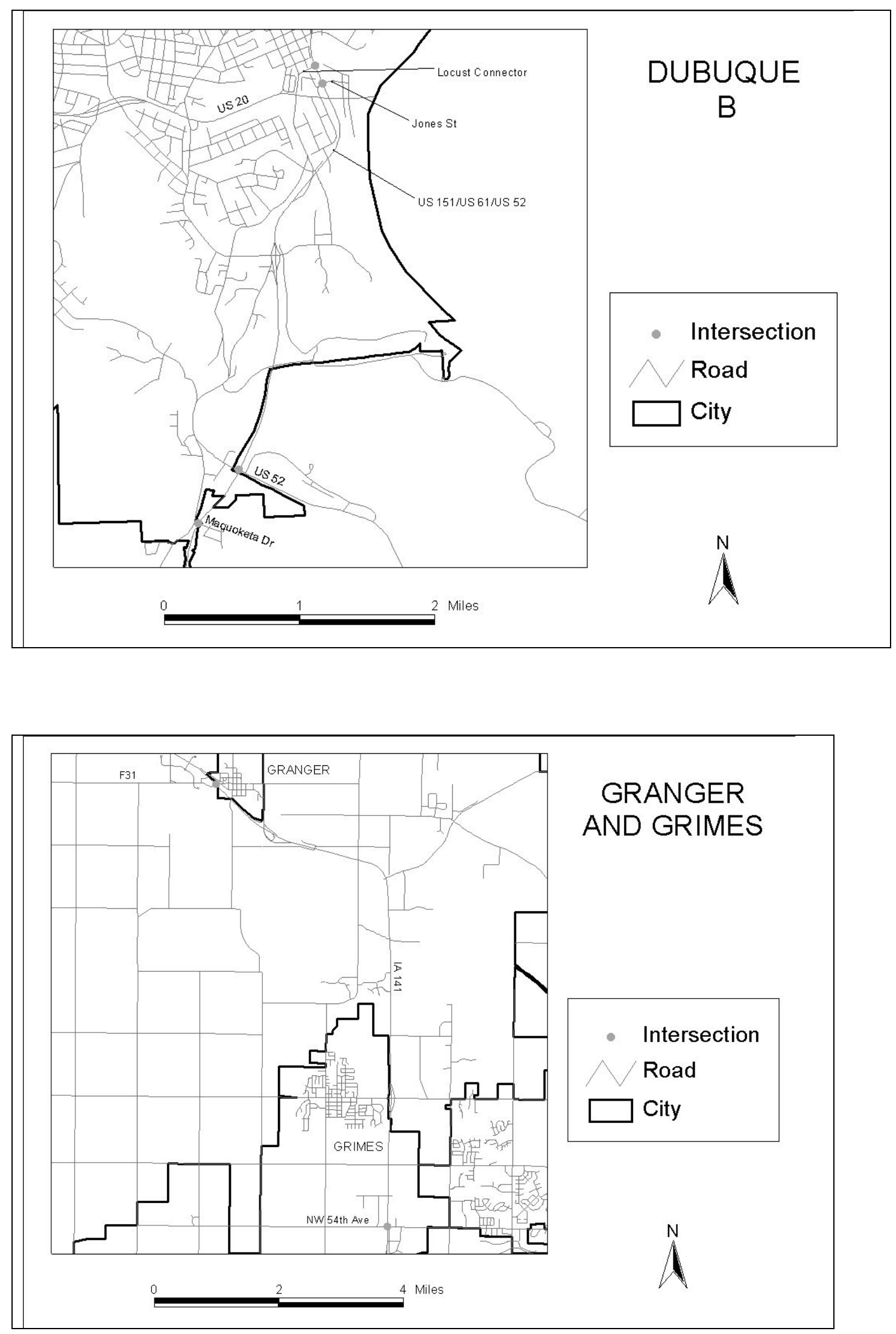

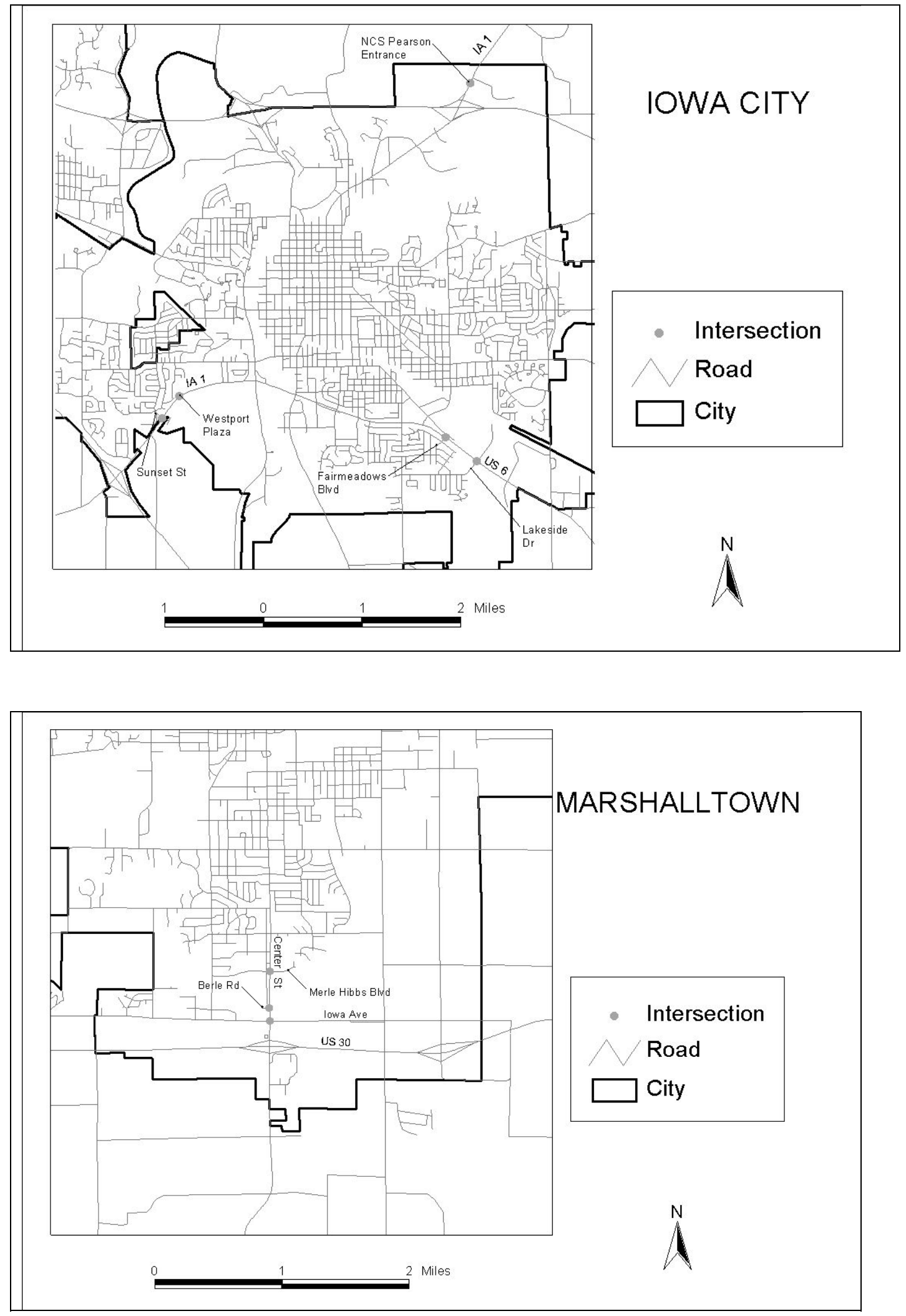

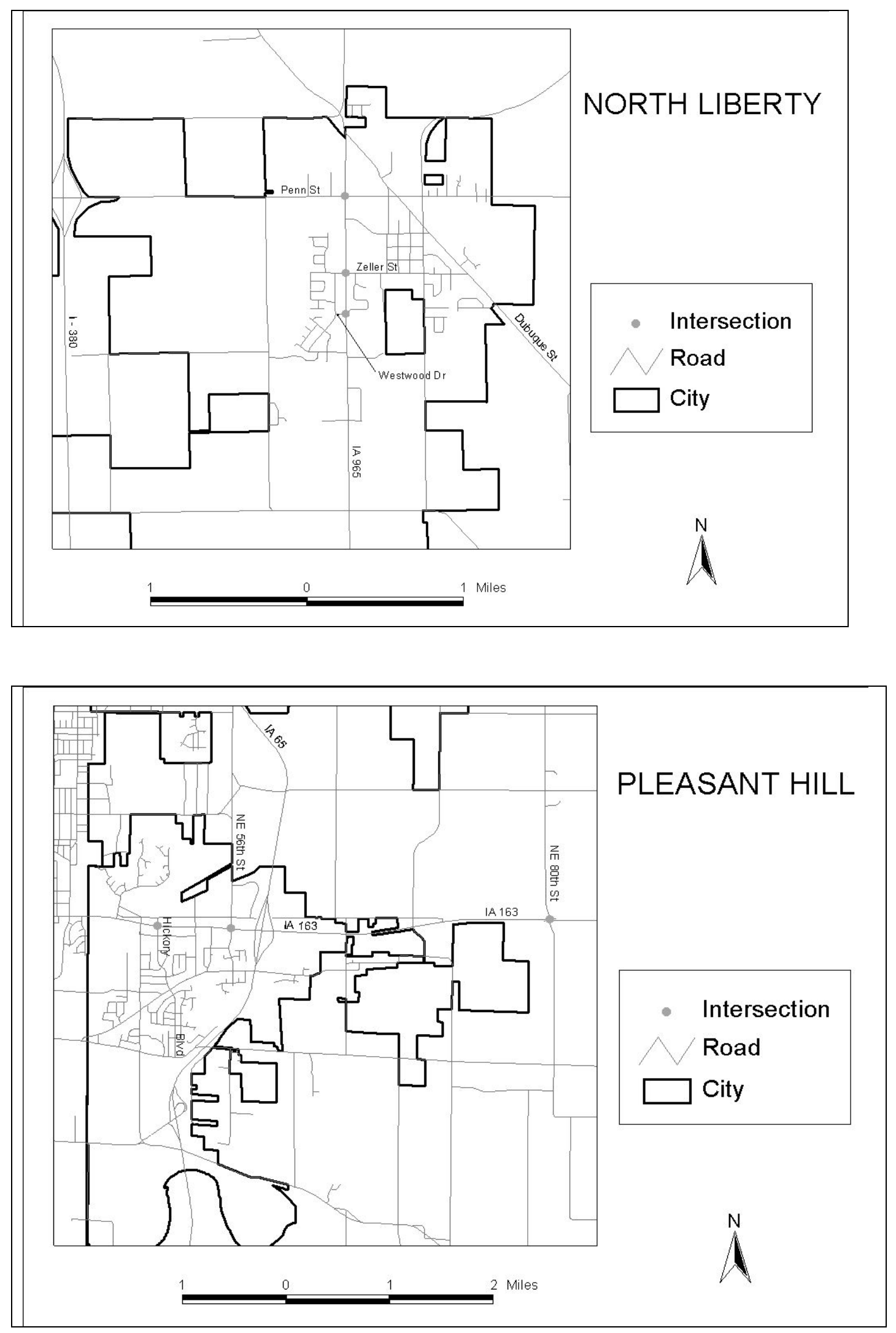

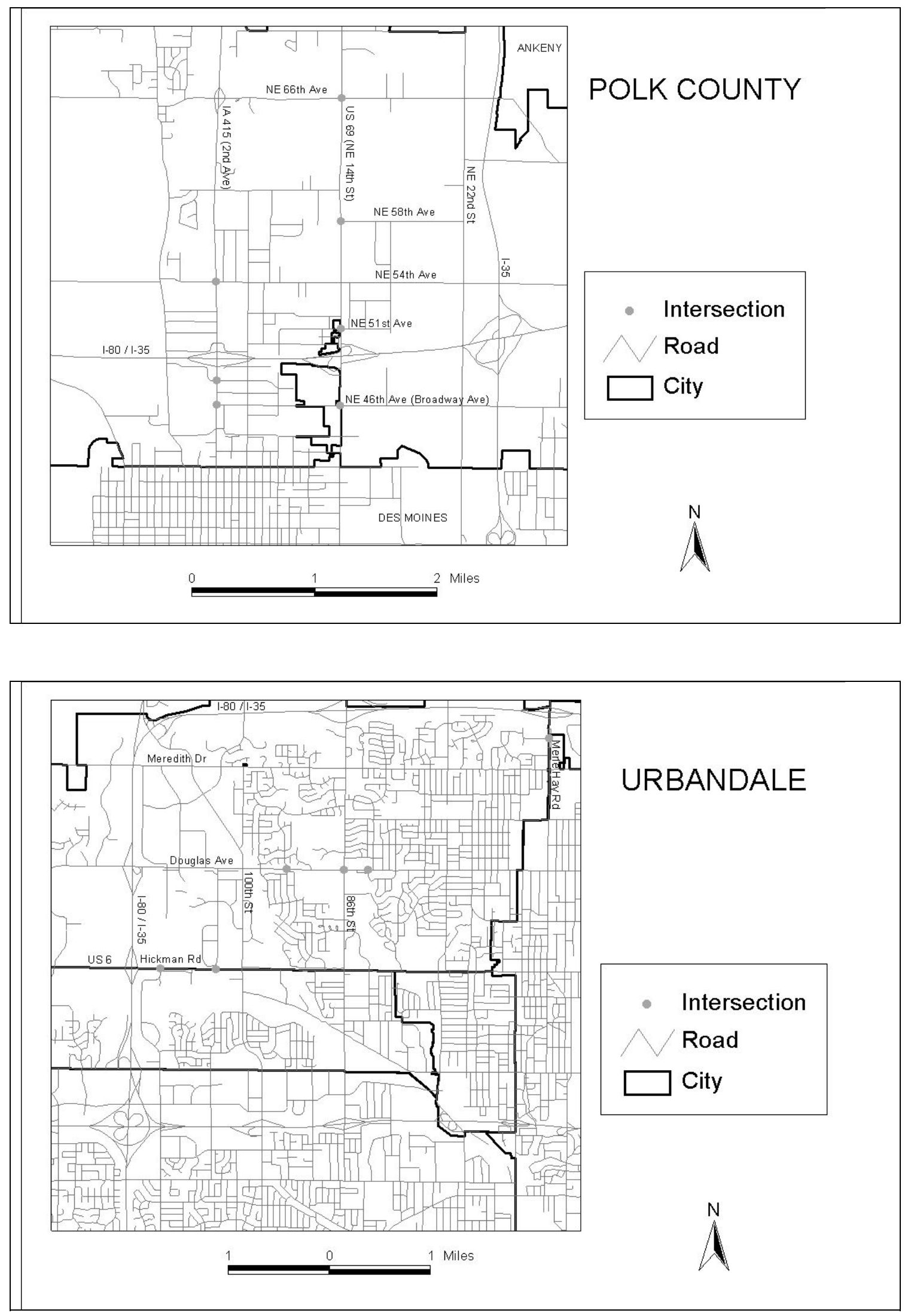

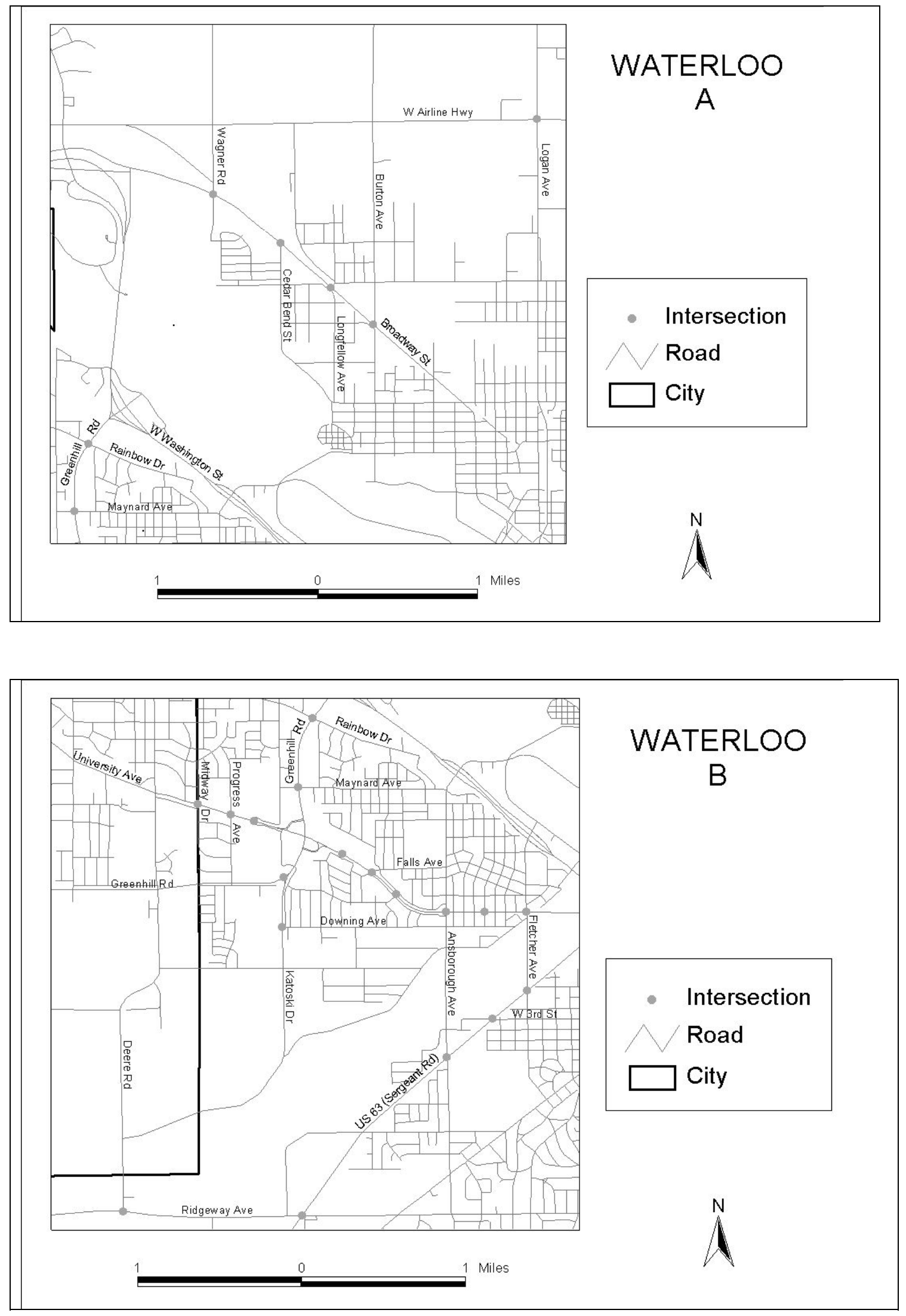


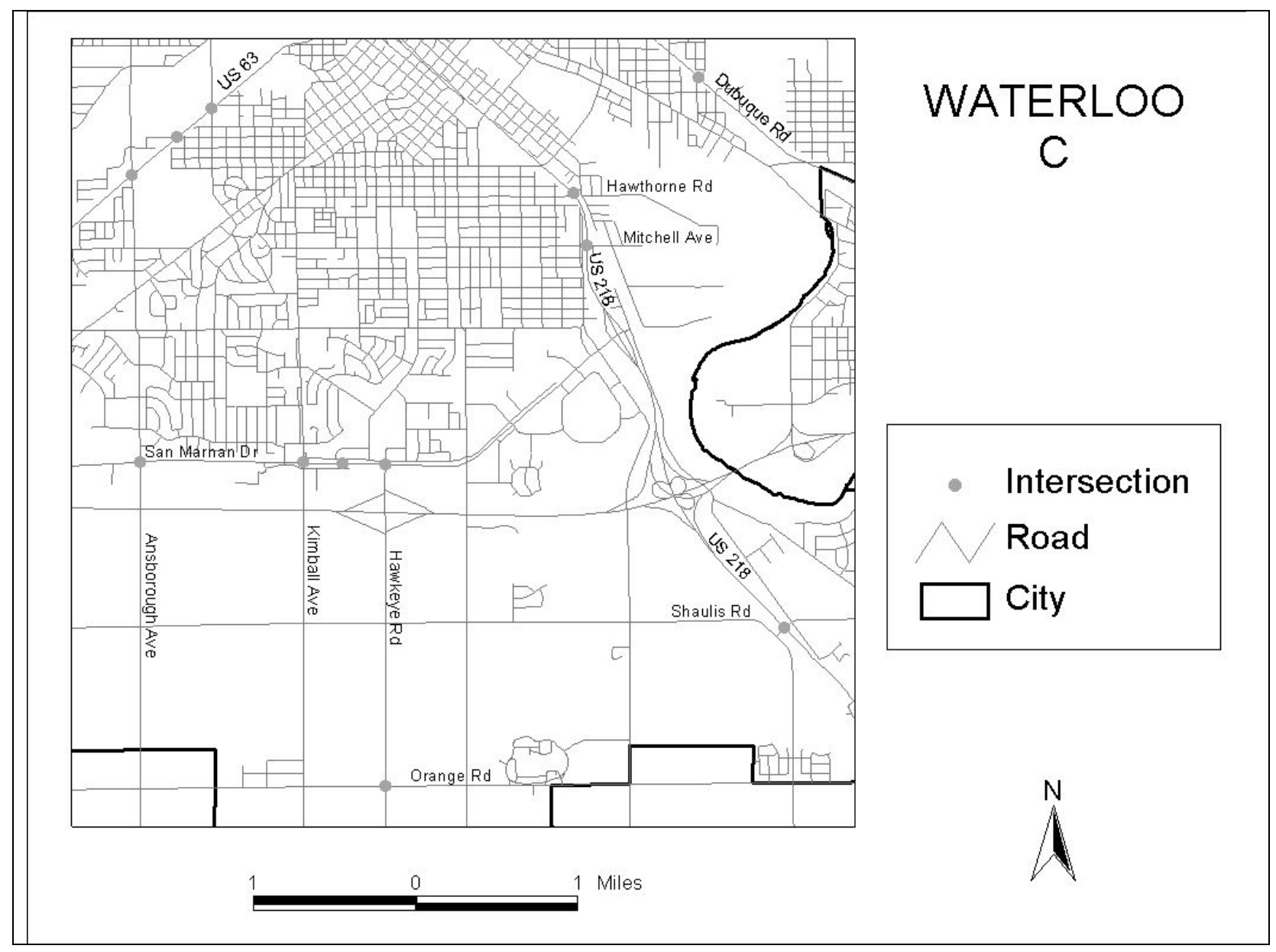




\section{APPENDIX C: IN-DEPTH DESCRIPTION OF METHODOLOGY}

The following section offers in-depth description of the statistical methods used in this study.

\section{Left-Turn Crash Rates by Type of Left-Turn Phasing}

Crash analysis typically uses some method to determine not only the number of crashes (frequency) but also a measure of exposure (crash rate). Crash frequency is not appropriate for evaluating whether older or young drivers are involved in certain types of crashes since the number of crashes provides no indication of the actual potential for them to be involved. For instance, a small frequency of nighttime crashes for older drivers may not be significant if older drivers are driving at night at the same rate as drivers of other ages. If a much smaller percentage of older drivers drive at night as compared to younger drivers, a small frequency of crashes may be significant. Using crash rates is more appropriate than frequency according to Golias and Yannis (2001). In order to calculate crash rates, however, a measure of exposure such as vehicle miles traveled (VMT) or number of licensed drivers in each category must be available and truly representative of the location under study. VMT by age group is difficult to obtain on a local or even state level. National studies, such as the National Personal Transportation Study (NPTS), assign VMT fractions by different age groups. However, national statistics may not be representative of other areas. Others have used the number of licensed drivers statewide in each age group (McKelvey and Stamatiais 1989). However, while this provides a measure of the number of potential drivers, this method assumes that all drivers drive an equal amount of miles.

Hauer (2001) recommends that when crash rates are used, the units in the numerator should match the units in the denominator. For instance, the numerator should not be based on the number of crashes if the denominator is based on millions of entering vehicles (MEV) for a particular intersection. Instead, the numerator should be based on number of passenger cars or trucks, for example, if the denominator is based on MEV. Similarly, evaluating crash risk for a particular age group should be based on the number of persons present in that age group. The induced exposure method was used to determine the distribution of drivers by age group, as discussed in the following sections.

\section{Induced Exposure}

Because of the lack of exposure data for different age groups, a number of studies have used the induced exposure method, or, more specifically, the quasi-induced exposure method, to estimate exposure. The relative accident involvement ratio (RAIR) is typically calculated by dividing the percentage of drivers in a certain age group who are responsible in a crash by the percentage of drivers in the same age group who are not responsible.

According to Golias and Yannis (2001), the induced exposure method is based on the assumption that, in a two-vehicle crash, there is one driver who is responsible for the crash with a randomly "chosen" second driver who is not responsible. Since the induced exposure method assumes the driver who was not responsible was randomly chosen, the distribution of nonresponsible drivers theoretically approximates the distribution of all drivers. Therefore, the induced exposure method overcomes the need to obtain the number of miles traveled for each age group as the basis for exposure. Instead, the distribution of non-responsible drivers provides the exposure measure. 
The general form for the RAIR, as given in Stamatiadis and Deacon (1995) is the following:

$$
\operatorname{RAIR}_{i, j}=\frac{\frac{D 1_{i, j}}{\Sigma \Sigma D 1_{i, j}}}{\frac{D 2_{i, j}}{\Sigma \Sigma D 2_{i, j}}}
$$

In this formula, $i$ represents type $i$ drivers and $j$ represents type $j$ conditions. Therefore, $\mathrm{D} 1_{i, j}$ represents type $i$ drivers that are responsible under type $j$ conditions and D $2_{i, j}$ represents type $i$ drivers that are not responsible under type $j$ conditions.

The induced exposure method is based on several assumptions. First, correct assignment of fault or responsibility depends on the police officer's ability to determine which driver is responsible (Preusser et al. 1998) as well as willingness to take the time to record the circumstances of the crash correctly. Furthermore, the distribution of non-responsible drivers is assumed to be similar to the driving population as a whole and does not consider that certain segments of the population are more or less likely able to avoid being involved in a crash. For instance, younger drivers may be more likely to react to a situation and take evasive action than older drivers. The induced exposure method also assumes that the responsible drivers are not correlated to the population of non-responsible drivers. Stamatiadis and Deacon (1997) evaluated this assumption and found that the assumption is violated to some degree because similar drivers tend to drive at similar times and along similar routes. Errors in exposure estimation can be reduced if the crash data are disaggregated by time and location. However, after further study of the induced exposure method, Stamatiadis and Deacon found that the method provides adequate estimates of exposure to multi-vehicle crashes when better exposure data are not available.

\section{Calculation of Exposure by Age Group}

A variation of the induced exposure was used to estimate crash involvement by age group. Normally the induced exposure method compares drivers involved in a specific type of crash and situation of interest. For instance, the number of responsible drivers for a particular age group in a head-on collision would be divided by the number of non-responsible drivers in that age group who were also involved in a head-on collision. A ratio higher than one typically indicates overinvolvement. However, in this study, only 117 crashes were available. Subdividing the data by left-turn phasing and age group resulted in extremely small sample sizes. Additionally, the induced exposure method does not account for differences in volume between different three types of left-turn phasing. Protected left-turn phasing may be more likely at intersections with higher approach volumes and permitted phasing at intersections with lower approach volumes. The induced exposure method is not able to account for variations between sites. Consequently, it was decided that a modification to the induced exposure method was the best approach.

Drivers were divided into three ages groups: young (14- to 24-year-old), middle-age (25- to 64year-old), and older (65-year-old and older). Smaller age groups such as 14 to 18,19 to 24 , etc. were desirable. However, the low number of crashes resulted in small samples when divided by age and type of left-turn phasing. Consequently, those three age groups were decided to be the most reasonable. 
Exposure was determined by calculating the ratio of non-responsible drivers in a particular age group to all non-responsible drivers and then multiplying this ratio by approach volume. This resulted in an estimate of the number of drivers present by age group at a particular location or type of location. Ideally, a measure of exposure that represents the movement under consideration is used to calculate crash rate. However, left-turn volumes were not available by movement for all intersections, and project resources were not sufficient to collect left-turn volumes at all applicable intersection approaches. Moreover, the distribution of drivers was determined from non-responsible drivers who were not necessarily attempting to make a left turn prior to the crash. Therefore, the distribution of left-turning drivers could not be estimated using the distribution of non-responsible drivers. Consequently, volume by approach was used rather than left-turn volumes as the measure of exposure with the assumption that the distribution of left-turning drivers at a specific approach is not different than the distribution of all drivers at an intersection.

Million entering vehicles by approach were determined from AADT estimates, which were discussed in Section 2.4. For each approach, MEV was calculated according to equation (2). Since the AADT counts represent two-way volumes, the AADT counts were divided by two, assuming that AADT is split evenly between the two approaches.

$$
M E V_{j}=\frac{\left(\frac{A A D T_{k}}{2}\right) * 365}{1,000,000}
$$

where:

$M E V_{j}=$ MEV on the $j^{\text {th }}$ approach

$A A D T_{k}=A D T$ on selected approach for the $k^{\text {th }}$ year

The ratio of drivers for each age group was determined by selecting all two-vehicle crashes within a mile of each study intersection and determining which of the two drivers had the most contributing circumstance leading to the crash. An additional data field is available in which the officer reports the contributing circumstances, such as "ran traffic control," that resulted in the crash. This data field was used to determine which driver was more likely to be responsible in a crash. Therefore, the concept of least or most contributing circumstance was used to describe the induced exposure measure rather than "at fault" or "not at fault." The driver with the most significant contributing circumstance will be referred to as "Driver 1" and the driver with the less significant contributing circumstance will be referred to as "Driver 2". The number of drivers labeled as Driver 2 for all intersections were used to determine the percentage of drivers in each age group. The ratio of drivers by age group was calculated by dividing the number of drivers labeled as Driver 2 in a particular age group by the total number of drivers labeled as Driver 2. A total of 961 two-vehicle crashes were available for the study intersections. Younger drivers (14 to 24 ) made up $24.1 \%$ of Driver 2 category. Similarly, $67.6 \%$ of drivers in the middle-age group (25 to 64) and 8.2\% in the older driver category (65+) were listed as Driver 2.

The number of entering vehicles for each age group at each approach was then calculated using the ratio of drivers in each age group. $\mathrm{MEV}_{\mathrm{j}}$ was calculated according to the following equation: 


$$
\begin{aligned}
& M E V_{i j}=M E V_{j}^{*} R_{i} \\
& M E V_{i j}=\text { million entering vehicles for } i^{\text {th }} \text { age group at the } j^{\text {th }} \text { approach } \\
& M E V_{j}=\text { million entering vehicles for the } j^{\text {th }} \text { approach } \\
& R_{i}=\text { ratio of drivers for the } i^{\text {th }} \text { age group }
\end{aligned}
$$

Crash rates were calculated by summing the number of drivers in left-turn crashes that were labeled as Driver 1 under a certain set of circumstances and dividing by the total MEV for the same set of circumstances. For instance, to calculate the crash rate of young drivers at approaches with protected left-turn phasing, the total number of young drivers labeled as Driver 1 at approaches with protected phasing was divided by the sum of MEV, as calculated by equation (3), for young drivers at all approaches with protected phasing.

\section{Poisson Regression}

Another method that can be used to analyze data is regression analysis. Regression analysis is used to determine the degree of the relationship between several independent variables and a response variable. For this analysis, the response variable was the crash rate, which is the ratio of the number of crashes to the number of entering vehicles. Poisson regression was considered the most appropriate method of analysis since the Poisson distribution describes the probability of rare events occurring based on an infinite number of trials. Since crashes are considered extremely rare events, crashes are often assumed to be Poisson distributed.

The probability mass function for the Poisson distribution is given by the following equation:

$$
P\left(Y=k \mid X_{1}, X_{2}, \ldots, X_{p}\right)=\frac{\mu^{k} e^{-\mu}}{k !}, \text { for } k=0,1,2, \ldots
$$

This equation determines the probability of $k$ events occurring given a certain set of circumstances, such as $X_{1}, X_{2}, \ldots, X_{p}$. In this equation, $\mu$ represents the average number of occurrences. The log of the mean is assumed to be linearly related to $X_{1}, X_{2}, \ldots, X_{p}$, as shown below.

$$
\log (\mu)=\beta_{0}+\beta_{1} X_{1}+\ldots+\beta_{p} X_{p}
$$

Equation (5) can be modified to account for exposure. Since the number of crashes is dependent upon the number of entering vehicles, the log of a rate can be assumed to be linearly related to the independent variables, which is shown in the following equation. In this equation, $N$ is equal to the number of million entering vehicles.

$$
\log \left(\frac{\mu}{N}\right)=\beta_{0}+\beta_{1} X_{1}+\ldots+\beta_{p} X_{p}
$$


Using properties of logarithms, equation (6) can be modified so $\log (\mu)$ can still be modeled. The logarithm of $N$ is now considered an offset variable, i.e., the logarithm of $N$ has a coefficient of one for each observation.

$$
\log (\mu)=\log (N)+\beta_{0}+\beta_{1} X_{1}+\ldots+\beta_{p} X_{p}
$$

Once the analysis has been performed, the crash rate can be calculated for various situations by modifying equation (7) to obtain the following equation:

$$
\frac{\mu}{N}=e^{\beta_{0}+\beta_{1} X_{1}+\ldots+\beta_{p} X_{p}}
$$

In Poisson regression, the coefficients are estimated by the maximum likelihood method. The maximum likelihood method involves maximizing the likelihood as shown in equation (9),

$$
L(\beta)=\prod_{i=1}^{n} \frac{\mu_{i}^{y_{i}} e^{-\mu_{i}}}{y_{i} !}
$$

or, similarly, maximizing the log of the likelihood as represented by equation (10) with respect to the unknown parameters $\beta=\left(\beta_{0}, \beta_{1}, \ldots, \beta_{p}\right)$, where $\log \left(\mu_{i}\right)=\log \left(N_{i}\right)+\beta_{0}+\beta_{1} X_{i 1}+\ldots+\beta_{p} X_{i p}$ for the $i^{\text {th }}$ observation.

$$
\log L(\beta)=\sum\left\{y_{i} \log \left(\mu_{i}\right)-\mu_{i}\right\}
$$

Since the value of the logarithm of the likelihood (or log likelihood) measures the fit of the model, the log likelihood value can be used to compare the fit of one model to another.

For Poisson regression, it is assumed that the mean is equal to the variance. To determine if this assumption is met, the value of the deviance or Pearson Chi-Square can be divided by the degrees of freedom, which is equal to n-p-1, i.e., the number of observations minus the number of parameters. The deviance usually takes the following form:

$$
D=2 \sum\left\{y_{i} \log \left(\frac{y_{i}}{\hat{\mu}_{i}}\right)-\left(y_{i}-\hat{\mu_{i}}\right)\right\}
$$

In this equation, $\log \left(\hat{\mu}_{i}\right)=\log \left(N_{i}\right)+\hat{\beta}_{0}+\hat{\beta}_{1} X_{i 1}+\ldots+\hat{\beta}_{p} X_{i p}$, and $\hat{\beta}_{0}, \hat{\beta}_{1}, \ldots, \hat{\beta}_{p}$ are the maximum likelihood estimates of $\beta_{0}, \beta_{1}, \ldots, \beta_{p}$.

The Pearson Chi-Square is calculated by the following equation: 


$$
\chi_{p}^{2}=\sum \frac{\left(y_{i}-\hat{\mu}_{i}\right)^{2}}{\hat{\mu}_{i}} .
$$

Both the deviance and the Pearson Chi-Square divided by the degrees of freedom have a ChiSquared distribution with n-p-1 degrees of freedom. Values close to 1 for both the deviance and the Pearson Chi-Square indicate that the mean is equal to the variance. However, values that greatly exceed one indicate the presence of over-dispersion (when the variance is greater than the mean), and values less than one indicate the presence of under-dispersion (when the variance is less than the mean). There are methods to account for extra-dispersion (under-dispersion or overdispersion). For instance, the Negative Binomial distribution is typically used instead of the Poisson distribution if over-dispersion is present since the Negative Binomial distribution assumes the variance is greater than the mean.

For this analysis, the response variable was crash rate. The number of crashes was determined for each of the three age groups at each approach using the modified induced exposure method described in this section. A particular age group at particular approach represented an observation. The offset was the log of the MEV to account for exposure. Since Poisson regression can account for variables such as opposing speed and opposing ADT, which can differ between each approach, a method to account for the different distributions of drivers among the approaches was developed. As previously mentioned, crashes that occurred at each intersection within a one-mile radius were collected. At some intersections, however, very few crashes occurred. Therefore, the distribution of drivers by age was averaged from intersections located in the same city or in the same vicinity. For example, Grimes and Granger each had only one intersection included in the study. These two intersections formed one group since the intersections are located relatively close together on IA 141. To account for the differences in the number of crashes that were collected at each intersection within a group of intersections, a weighted average for each age group was calculated as demonstrated by equation (13):

$$
P_{i}=\frac{p_{i 1} * n_{1}+p_{i 2} * n_{2}+\ldots+p_{i k} * n_{k}}{n_{1}+n_{2}+\ldots+n_{k}}=\frac{x_{i 1}+x_{i x}+\ldots+x_{i k}}{n_{1}+n_{2}+\ldots+n_{k}}
$$

where:

$P_{i}=$ weighted average percent for the $i^{\text {th }}$ age group in a group of $k$ intersections

$p_{i j}=$ percent of Driver 2 in the $i^{\text {th }}$ age group for the $j^{\text {th }}$ intersection

$n_{j}=$ total number of Driver 2 for the $j$ th intersection

$x_{i j}=$ number of Driver 2 in the $i^{\text {th }}$ age group for the $j^{\text {th }}$ intersection

For each group of intersections, each percentage was weighted by multiplying the percentage of drivers by the number of drivers in the respective age group from the respective intersection. The weighted percentages were then added together and divided by the sum of all drivers from each intersection. This is equivalent to dividing the sum of all drivers in one age group from a group of intersections by the total number of drivers. 
Using the distribution of drivers for each group of intersections, the MEV for each approach was divided among the three age groups. The MEV was multiplied by the percentage that corresponds to the age group and the group of intersections that includes the respective approach as demonstrated by the following equation.

$$
M E V_{i j}=M E V_{j} * P_{i j}
$$

where:

$M E V_{i j}=$ million entering vehicles for $i^{\text {th }}$ age group at the $j^{\text {th }}$ approach

$M E V_{j}=$ million entering vehicles for the $j^{\text {th }}$ approach

$P_{i j}=$ percentage of drivers for the $i^{\text {th }}$ age group at the $j^{\text {th }}$ approach

Crash rate was the dependent variable. The independent variables used in the Poisson regression analysis included the following:

- Type of left-turn phasing

- Age group

- Speed limit for opposing approach

- Number of left-turn lanes for the approach analyzed

- Number of through lanes on the opposing approach

- Total number of lanes on the opposing approach

- Minimum green time for the left-turn phase for protected phasing

- Length of the clearance interval for the left-turn phase

- ADT on the opposing approach

\section{Development Of Poisson Regression Model}

Forward regression was used to develop the model. The first model that was produced contained both age group and type of phasing as the independent variables. Several models with three variables were created by adding one of the remaining variables to age group and type of phasing. (Since the green arrow and clearance interval for the left-turn phase appear only during protected or protected/permitted phasing, separate models that omitted approaches under permitted phasing were developed. These models are discussed at the end of this section.) The three-variable model with the highest log likelihood value was considered the best model. The best model was created when opposing ADT was added to age group and type of phasing. This model was considered an improvement over the two-variable model since the log likelihood value for the model containing opposing ADT increased by 9.93 while only losing one degree of freedom. This difference is significant according to the Chi-Square table. Next, several fourvariable models were created by adding one of the remaining variables to age group, type of phasing, and opposing ADT. However, none of these models provided a better fit over the model with age group, type of phasing, and opposing ADT. A backward regression was also performed by removing the least significant variable until all the remaining variables met the 0.05 significance level. Again, the model with age group, type of phasing, and opposing ADT was found to be the best-fit model under this approach. Therefore, the best-fit model has three variables: age group, type of phasing, and opposing ADT. All three independent variables were found to be significant $(\mathrm{p}<0.0001)$. In addition, the deviance and the Pearson Chi-Square 
divided by the degrees of freedom were 0.61 and 1.11, respectively. These numbers do not provide evidence that there is over-dispersion among the data. According to the FHWA (1997), if the Pearson Chi-Square ratio is between 0.8 and 1.2, one can assume that the model fits the data adequately. Consequently, the best-fit model was found to be an improvement over the first model, as shown in Table C-1.

Table C.1. Model variables used to asses goodness of fit

\begin{tabular}{|l|l|}
\hline & Best Fit Model \\
\hline Deviance / df & 0.61 \\
\hline Pearson Chi-Square / df & 1.11 \\
\hline Log Likelihood & -258.66 \\
\hline Degrees of Freedom & 594 \\
\hline
\end{tabular}

The best-fit model indicates that the expected crash rate for protected phasing (A) is lower than for permitted phasing (C). Similarly, the expected crash rate for protected/permitted phasing (B) is higher than for permitted phasing; although, this difference is not statistically significant. To understand how the estimated coefficient describes the relationship between the crash rate and the independent variables, a comparison of the crash rates can be made by dividing the expected crash rate (according to equation [8]) under one set of circumstances by the expected crash rate under a slightly different set of circumstances. If one independent variable increases by one unit while all other variables remain constant, the ratio simplifies to $e^{\beta i}$. For example, the ratio of the expected crash rate for protected phasing and the expected crash rate for permitted phasing while controlling for the other independent variables is equal to $e^{-1.6311}=0.196$. Therefore, the expected crash rate for protected phasing is $1-0.196$, or $80.4 \%$ lower than the rate for permitted phasing. Similarly, the expected crash rate for protected/permitted phasing is $20.4 \%$ higher than the rate for permitted phasing, and the expected crash rate for protected phasing is $83.8 \%$ higher than the rate for protected/permitted phasing. Using the contrast option in the PROC GENMOD, likelihood ratio tests were calculated to determine if the differences between the three types of left-turn phasing were significant given a significance level of 0.05. From the results shown in Table C.2, the difference between protected phasing and the other two types of phasing are significant; however, the relationship between protected/permitted phasing and permitted phasing is not significant.

The model also shows that both young drivers (0) and middle-age drivers (1) have an expected crash rate that is less than the rate for older drivers (2) while controlling for all other independent variables in the model. The expected crash rate for young drivers is $35.9 \%$ lower than the rate for older drivers, but this difference is not statistically significant. Middle-age drivers are expected to have a crash rate that is $66.1 \%$ lower than the rate for older drivers and $47.1 \%$ lower than the rate for young drivers. Both of these differences were found to be significant.

Finally, opposing ADT was found to be significant. According to the model, for every one level increase in the opposing ADT (an increase of 5,000 vpd), the crash rate decreases by $46.0 \%$. Although this may be counterintuitive, it is likely that as volume increases, vehicles slow down and drivers may be more likely to pay attention. Additionally, left-turning drivers may be more 
likely to realize that they do not have the right-of-way when more vehicles are present in the opposing lanes than with lighter traffic.

Table C.2. Best fit model

\begin{tabular}{|l|l|l|l|l|l|l|l|}
\hline Parameter & DF & Estimate & $\begin{array}{l}\text { Standard } \\
\text { Error }\end{array}$ & \multicolumn{2}{l|}{$\begin{array}{l}\text { Wald 95\% } \\
\text { Confidence Limits }\end{array}$} & $\begin{array}{l}\text { Wald } \\
\chi^{2}\end{array}$ & Pr $>$ ChiSq \\
\hline Intercept & 1 & -0.8753 & 0.2922 & -1.4481 & -0.3026 & 8.97 & $\mathbf{0 . 0 0 2 7} *$ \\
\hline Phasing A & 1 & -1.6311 & 0.3287 & -2.2753 & -0.9868 & 24.62 & $<\mathbf{0 . 0 0 0 1 *}$ \\
\hline Phasing B & 1 & 0.1860 & 0.2168 & -0.2389 & 0.6109 & 0.74 & 0.3910 \\
\hline Phasing C & 0 & 0.0000 & 0.0000 & 0.0000 & 0.0000 & --- & -- \\
\hline Age_Grp 0 & 1 & -0.4454 & 0.2663 & -0.9673 & 0.0766 & 2.80 & 0.0944 \\
\hline Age_Grp 1 & 1 & -1.0823 & 0.2581 & -1.5882 & -0.5765 & 17.59 & $<\mathbf{0 . 0 0 0 1}^{*}$ \\
\hline Age_Grp 2 & 0 & 0.0000 & 0.0000 & 0.0000 & 0.0000 & --- & -- \\
\hline Opp_ADT & 1 & -0.6158 & 0.1397 & -0.8896 & -0.3420 & 19.43 & $<\mathbf{0 . 0 0 0 1 *}$ \\
\hline
\end{tabular}

*meets the alpha level of 0.05

Table C.3. Contrast results using the likelihood ratio test

\begin{tabular}{|l|l|c|l|}
\hline Contrast & DF & Chi-Square & Pr $>$ ChiSq \\
\hline Protected vs. Protected/Permitted & 1 & 52.59 & $<\mathbf{0 . 0 0 0 1}^{*}$ \\
\hline Protected vs. Permitted & 1 & 27.32 & $<\mathbf{0 . 0 0 0 1}^{*}$ \\
\hline Protected/Permitted vs. Permitted & 1 & 0.75 & 0.3856 \\
\hline Young vs. Middle-Age Drivers & 1 & 9.26 & $\mathbf{0 . 0 0 2 3} *$ \\
\hline Young vs. Older Drivers & 1 & 2.64 & 0.1041 \\
\hline Middle-Age vs. Older Drivers & 1 & 14.68 & $<\mathbf{0 . 0 0 0 1}^{*}$ \\
\hline
\end{tabular}

*meets the alpha level of 0.05

The results in Table C.3 only show the contrast between either the different types of phasing or age groups while holding all other independent variables constant. To examine the differences between all combinations of phasing type and age group, the estimate option was used in PROC GENMOD to determine the expected crash rate for each category and confidence intervals with $\alpha=0.05$. These results are provided in Table C.4. To calculate the expected crash rate, a value was chosen for the third independent variable, opposing ADT. Since most of the approaches fall in the level 1 category, a comparison was made using the value of 1 for opposing ADT. Therefore, the crash rates listed below are the expected crash rates when the opposing ADT is 5,000 to 9,999 vehicles. 
Table C.4. Expected crash rates and confidence intervals

\begin{tabular}{|l|l|l|l|l|}
\hline Phasing & Age Group & Expected Crash Rate & \multicolumn{2}{|l|}{ Confidence Interval, $\boldsymbol{\alpha}=\mathbf{0 . 0 5}$} \\
\hline Protected & 14 to 24 & 0.028 & 0.016 & 0.051 \\
\cline { 2 - 5 } & 25 to 64 & 0.015 & 0.009 & 0.026 \\
\cline { 2 - 5 } & $65+$ & 0.044 & 0.023 & 0.085 \\
\hline \multirow{3}{*}{$\begin{array}{l}\text { Protected/ } \\
\text { Permitted }\end{array}$} & 14 to 24 & 0.174 & 0.125 & 0.242 \\
\cline { 2 - 5 } & 25 to 64 & 0.092 & 0.067 & 0.125 \\
\cline { 2 - 5 } & $65+$ & 0.271 & 0.173 & 0.424 \\
\hline Permitted & 14 to 24 & 0.144 & 0.094 & 0.222 \\
\cline { 2 - 5 } & 25 to 64 & 0.076 & 0.051 & 0.114 \\
\cline { 2 - 5 } & $65+$ & 0.225 & 0.132 & 0.384 \\
\hline
\end{tabular}

Crash rates are statistically different if the two respective confidence intervals do not overlap. It should be noted that the expected crash rate listed in Table C. 4 is determined solely from the best-fit model, which does not consider the interactions between the age groups and the types of phasing. There is some evidence of interaction since the rate for young drivers under permitted phasing is higher than expected after examining the patterns among the other rates. Attempts were made to account for the interaction in the model. However, these attempts did not result in a significantly better model.

Finally, two other variables were considered: the minimum time for the green arrow and the length of the clearance interval for the left-turn phase. These two variables can only take on values greater than zero under protected phasing and protected/permitted phasing. Therefore, Poisson regression models were developed using approaches under protected and protected/permitted phasing only to test these two variables. When the length of the clearance interval was added to the model with age group, type of phasing, and opposing ADT, the length of the clearance interval was not found to be significant. When the minimum time for the green arrow was added, a reasonable, but not statistically significant, relationship $(\mathrm{p}=0.1617)$ was found. The estimate for the minimum time for the green arrow was -0.0798 , which means that there is a $7.7 \%$ reduction in the expected crash rate for every one-second increase in the minimum time for the green arrow. The relationships between all three age groups were found to be significant since permitted phasing was excluded from the model. In addition, the expected crash rates for young and middle-age drivers are $47.9 \%$ and $69.2 \%$ lower than the crash rate for older drivers, respectively. 


\section{APPENDIX D: CODE ASSIGNING CONTRIBUTING CIRCUMSTANCE IN CRASH DATABASE FROM METADATA FOR 2001 CRASHES}

\begin{tabular}{|c|l|}
\hline \multicolumn{2}{|l|}{ DContCirc1: Driver Contributing Circumstance } \\
From zdrv file \\
\hline 1 & Ran traffic signal \\
\hline 2 & Ran stop sign \\
\hline 3 & Exceeded authorized speed \\
\hline 4 & Driving too fast for conditions \\
\hline 5 & Made improper turn \\
\hline 6 & Traveling wrong way or on wrong side of road \\
\hline 7 & Crossed centerline \\
\hline 8 & Lost Control \\
\hline 9 & Followed too close \\
\hline 10 & Swerved to avoid: vehicle/object/non-motorist/or animal in roadway \\
\hline 11 & Over correcting/over steering \\
\hline & Operating vehicle in an erratic/reckless/careless/negligent/aggressive \\
12 & manner \\
\hline 13 & FTYROW: From stop sign \\
\hline 14 & FTYROW: From yield sign \\
\hline 15 & FTYROW: Making left turn \\
\hline 16 & FTYROW: Making right turn on red signal \\
\hline 17 & FTYROW: From driveway \\
\hline 18 & FTYROW: From parked position \\
\hline 19 & FTYROW: To pedestrian \\
\hline 20 & FTYROW: At uncontrolled intersection \\
\hline 21 & FTYROW: Other (explain in narrative) \\
\hline 22 & Inattentive/distracted by: Passenger \\
\hline 23 & Inattentive/distracted by: Use of phone or other device \\
\hline 24 & Inattentive/distracted by: Fallen object \\
\hline 25 & Inattentive/distracted by: Fatigued/asleep \\
\hline 26 & Other (explain in narrative): Vision obstructed \\
\hline 27 & Other (explain in narrative): Other improper action \\
\hline 28 & Other (explain in narrative): No improper action \\
\hline 99 & Unknown \\
\hline & \\
\hline
\end{tabular}

